SALINERO, Sebastián. "El crimen organizado en Chile. Una aproximación criminológica al perfil del delincuente a través de un estudio a una muestra no representativa de condenados por delitos de tráfico de estupefacientes".

Polít. crim. Vol. 10, No 19 (Julio 2015), Art. 2, pp. 25-55.

[http://www.politicacriminal.cl/Vol_10/n_19/Vol10N19A2.pdf]

\title{
El crimen organizado en Chile. Una aproximación criminológica al perfil del delincuente a través de un estudio a una muestra no representativa de condenados por delitos de tráfico de estupefacientes *
}

\section{Organized crime in Chile. A criminological approach to profile of offenders through a study of a non-representative sample of offenders convicted of drug trafficking}

Sebastián Salinero Echeverría

Abogado, Magíster en Derecho Penal de la Universidad de Talca. Doctor en Derecho de la Universidad de Lérida, España. Profesor de Derecho Penal y Criminología Universidad de

Talca.

ssalinero@utalca.cl

\section{Resumen}

El artículo basado en la metodología criminológica empírica realiza un estudio exploratorio y descriptivo de las organizaciones criminales en Chile. Para lo cual, ejecuta una encuesta a una muestra no representativa estadísticamente de personas que se encuentran purgando una pena privativa de libertad en un recinto penal chileno por algún delito de la Ley de Drogas, y con ello determinar la pertenencia a este tipo de entidades asociativas y el perfil de sus integrantes. Entre sus resultados, destaca la elevada presencia de organizaciones ilícitas y la transnacionalidad del fenómeno.

Palabras clave: Organización criminal, Criminología, Perfil del delincuente, Encuesta a reclusos, Mujeres, Transnacionalidad.

\begin{abstract}
This article based on empirical criminological methodology makes an exploratory and descriptive study of criminal organizations in Chile. For this, we do a survey of statistically unrepresentative sample of people who are in a chilean prison for a crime of Drugs Law, and determine the number of membership and profile of its members. The results show the high prevalence of illegal organizations and the nature transnational of the phenomenon.
\end{abstract}

Key words: Criminal organization, Criminology, Offender Profile, Survey of convicts, Women, Transnationality.

\footnotetext{
* El texto es parte del proyecto Fondecyt N N 1130406, a cargo del Dr. Raúl Carnevali, titulado "La criminalidad organizada: examen desde una perspectiva jurídica y política". Además este estudio fue presentado en el seminario "Análisis de la criminalidad organizada desde tres perspectivas", celebrado el 21 de enero en la Ciudad de Talca.
} 
SALINERO, Sebastián. "El crimen organizado en Chile. Una aproximación criminológica al perfil del delincuente a través de un estudio a una muestra no representativa de condenados por delitos de tráfico de estupefacientes".

\section{Presentación y objetivos del trabajo.}

En general los estudios criminológicos empíricos son escasos en Chile, salvo algunos trabajos desarrollados por distintas instituciones como la Fundación Paz Ciudadana y el Centro de Estudios en Seguridad Ciudadana (CESC), y algunos esfuerzos personales provenientes del mundo académico en general. Conocido este déficit, debemos señalar que el conocimiento que se tiene desde la Criminología sobre las organizaciones criminales que desarrollan sus actividades ilícitas -y que operaron- en el país son escasos por no decir nulos. Incluso, a algunos les podría parecer que las organizaciones criminales no existen o no son parte de nuestra coyuntura y están asociadas a otras realidades sociales como la europea o la estadounidense, o, más bien son parte del repertorio cinéfilo de destacados filmes como "El Padrino" o " Cara cortada", por destacar los más emblemáticos sobre la temática.

Las aproximaciones al fenómeno de las organizaciones criminales en Chile se pueden reducir por una parte a una escueta mirada jurídico penal, y mayoritariamente por otra parte al ámbito periodístico investigativo, el que se ha limitado a reportar la existencia de estos grupos dedicados a quehaceres delictuales, dando cuenta de sus características y de la inusual vida de sus miembros. Paradigma de esto último, son las noticias publicadas en los medios de comunicación de distintas bandas que bajo una estructura jerarquizada, se dedican a la empresa criminal. Ejemplos de las mismas sobran por doquier. En la década del 60 destacaba la banda del "Cabro Carrera" integrante del conocido "sindicato del crimen", y últimamente aparecen en la palestra los bullados casos de "Los Cavieres", "Los cara de jarro" o "Los cara de pelotas", organizaciones dedicadas al negocio de la droga y que aparentemente han sido desbaratadas por la policía.

Por otra parte, cabe preguntarnos cómo nos puede ayudar la Criminología respecto de este fenómeno. Debiendo puntualizar previamente que la Criminología como ciencia empírica e interdisciplinaria tiene diversos objetos de estudio: el delito, sea éste como acontecimiento individual o social; la persona del delincuente, visto desde una perspectiva bio-psico-social; la víctima del delito; y finalmente el control social del comportamiento desviado. En base a estos objetivos, establecidos de manera muy general, esta ciencia persigue diversas finalidades: aportar información sobre la realidad del fenómeno criminal; las causas o etiología del mismo; la prevención y control de la criminalidad; y para terminar de intervención, lo que se traduce en dar una respuesta al delito y ocuparse del tratamiento resocializador del delincuente ${ }^{1}$.

Señalado lo anterior a modo introductorio, es que nos hemos propuesto realizar un abordaje criminológico exploratorio y descriptivo de las organizaciones criminales en Chile, basado específicamente en la reseña de las tesis criminológicas clásicas o tradicionales que han intentado explicar estas organizaciones y, por otra parte, presentar los resultados de un estudio empírico, consistente en una encuesta realizada a una muestra no representativa

\footnotetext{
${ }^{1}$ GARCÍA-PABLOS DE MOLINA, Antonio, Tratado de Criminología, $4^{\mathrm{a}}$ Ed. Valencia: Tirant lo Blanch, 2009, p. 54.
} 
Polít. crim. Vol. 10, № 19 (Julio 2015), Art. 2, pp. 25-55.

[http://www.politicacriminal.cl/Vol_10/n_19/Vol10N19A2.pdf]

estadísticamente de personas que se encuentran purgando una pena privativa de libertad en un recinto penal chileno, siendo el común denominador que las caracteriza, que todas ellas están condenadas por algún delito de la Ley de Drogas.

\section{Conceptualización del crimen organizado.}

La oficina Federal de Investigaciones norteamericana (FBI) define crimen organizado como

"un conjunto de individuos o grupos que se asocian de manera estructurada y disciplinada con el fin de obtener ganancias o beneficios monetarios y comerciales en todo o parte- por medios ilícitos". 2

Desde el punto de vista dogmático penal, la importancia de saber qué se entiende por crimen organizado es fundamental, no solo por la consecuencia jurídica (pena) para el autor, sino también porque la determinación de sus presupuestos permite distinguir aquellos casos en los que estamos frente a una especial figura delictiva, de aquellos supuestos de codelincuencia ${ }^{3}$. Por su parte, para la Criminología, como se indicará infra, uno de los grandes inconvenientes en la investigación del crimen organizado también ha sido poder determinar su contenido conceptual, lo que lógicamente ha generado escasez de evidencia empírica al respecto. Así, podemos decir que la determinación conceptual del fenómenos para ambas disciplinas de las ciencias penales, no es un tema baladí, sino fundamental y, respecto del cual, la solución sólo vino dada desde el concierto internacional, en particular por la Convención de las Naciones Unidas contra la delincuencia organizada transnacional, conocida como convención de Palermo ${ }^{4}$, la que además de estar dirigida a definir instrumentos que permitan conformar una estrategia común entre los Estados contra esta especialidad en el crimen, vino a definir en su Art. 2, lo que se entiende por grupo delictivo organizado:

"un grupo estructurado de tres o más personas que existe durante cierto tiempo y que actúa concertadamente con el propósito de cometer uno o más delitos graves o delitos tipificados con arreglo a la presente Convención con miras a obtener, directa o indirectamente, un beneficio económico u otro beneficio de orden material".

Esta definición vino a superar los inconvenientes que otrora existían, ya que dentro de la categoría de crimen organizado se concebía una amplia variabilidad de grupos, actividades y formas de desarrollar el mismo que dificultaban el diseño de una definición común.

La definición alcanzada en Palermo va en la línea de las propuestas europeas de definición del crimen organizado (Europol, etc.) y comparte también su misma filosofía como esgrime Giménez- Salinas, toda vez que flexibiliza el concepto para incorporar en él prácticamente

2 Véase la Federal Bureau of Investigation en: http://www.fbi.gov/aboutus/investigate/organizedcrime/glossary. [fecha de visita el 16 de enero de 2014].

3 CARNEVALI, Raúl, "Las organizaciones criminales. Algunas cuestiones a considerar para su configuración", Doctrina y Jurisprudencia Penal, Universidad de Los Andes, nº 14 (2013), pp. 3-22, p. 3.

${ }^{4}$ La Convención contra la Delincuencia Organizada Transnacional, se suscribió en Palermo (Italia) en diciembre del año 2000. Véase Convención En: www.acnur.org/biblioteca/pdf/1292.pdf [fecha de visita el 16 de enero de 2014]. 
SALINERO, Sebastián. "El crimen organizado en Chile. Una aproximación criminológica al perfil del delincuente a través de un estudio a una muestra no representativa de condenados por delitos de tráfico de estupefacientes".

a cualquier grupo que se dedique a procurar un beneficio económico con la acción delictiva $^{5}$. Sin embargo, así entendido el crimen organizado, es posible que se equiparen distintas agrupaciones y en, consecuencia, reciban el mismo tratamiento jurídico penal. Bajo este concepto, se podría localizar la conocida mafia, las pandillas juveniles, los grupos terroristas, etc. Pareciera, a nuestro juicio, que el concepto no pone atención en lo realmente importante, y es que una organización ilícita puede erosionar gravemente las instituciones del Estado, corrompiendo funcionarios, generando percepciones de inseguridad pública, con el correspondiente quebrantamiento de Estado de derecho ${ }^{6}$.

Por lo anterior, como arguye Giménez-Salinas, la categoría de crimen organizado debe quedar reservada para designar la forma superior de asociación criminal o las más graves representaciones de estas colectividades. En base a aquello, propone una definición criminológica de organización criminal o grupo de crimen organizado que interpreta adecuadamente el sentido de estas agrupaciones y que justifica una especial respuesta penal, señalando que se debe concebir como:

"Cualquier organización creada con el propósito expreso de obtener y acumular beneficios económicos a través de su implicación continuada en actividades predominantemente ilícitas y que asegure su supervivencia, funcionamiento y protección mediante recurso a la violencia y la corrupción o la confusión con empresas legales". 7

Una conceptualización así lograda, nos permite realizar una disquisición entre organizaciones criminales de lo que son las pandillas juveniles y el terrorismo. Mientras la primera tiene una inminente finalidad económica como una empresa, las pandillas juveniles buscan alcanzar una identidad propia, un medio y estilo de vida alternativo para sus miembros ${ }^{8}$. A su vez, las organizaciones terroristas, las que si bien también son criminales ${ }^{9}$, tienen otros objetivos principales prioritarios, como políticos, religiosos, etc. Si bien las pandillas juveniles y las organizaciones terroristas pueden cometer algunos delitos con una finalidad económica, lo cual puede ser frecuente, esa función es instrumental o medial, respecto de sus verdaderos objetivos ${ }^{10}$.

Sin perjuicio de que el concepto criminológico propuesto es el correcto para llenar el contenido de lo que es una organización criminal, para los efectos del trabajo empírico que se expondrá a continuación hemos elegido como marco teórico el concepto de Palermo por

\footnotetext{
5 GIMÉNEZ-SALINAS, Andrea, El crimen organizado, Barcelona: Ediciones Universidad Oberta de Cataluña, 2013, pp.1-58, p. 8.

6 CARNEVALI, Raúl, "La criminalidad organizada. Una aproximación al Derecho penal italiano, en particular la responsabilidad de las personas jurídicas y la confiscación", Revista Ius et Praxis, Año 16, № 2 (2010), pp. 273-330, p. 277.

7 GIMÉNEZ-SALINAS, Andrea, "La delincuencia organizada en Europa: Extensión, factores facilitadores y rasgos principales", Documentos de seguridad y defensa, № 48 (2012), pp. 11-32, p. 14.

${ }^{8}$ VÁSQUEZ, Carlos; SERRANO, María Dolores, Derecho penal juvenil, $2^{\mathrm{a}}$ Ed. Madrid: Dykinson, 2007, p. 48.

${ }^{9}$ CARNEVALI, "La criminalidad", cit. nota ${ }^{\circ}$ 6, p. 276.

${ }^{10}$ GIMÉNEZ-SALINAS, El crimen, cit. nota ${ }^{\circ}$ 5, p. 11.
} 
Polít. crim. Vol. 10, No 19 (Julio 2015), Art. 2, pp. 25-55.

[http://www.politicacriminal.cl/Vol_10/n_19/Vol10N19A2.pdf]

las razones que se expresan en el apartado metodológico.

\section{Investigaciones empíricas sobre las organizaciones criminales: Estado de la cuestión y la problemática asociada a su investigación.}

En los años veinte, John Landesco llevó a cabo un estudio pionero sobre el crimen organizado, cuyo título original es "Organized crime in Chicago"11, en el que revela las relaciones históricas entre los barrios desorganizados, los mercados ilícitos y la economía política de los Estados Unidos urbano. Sin duda una de las virtudes de este trabajo es que introdujo el método de las entrevistas en profundidad con actores relevantes, como delincuentes e informantes, en el abanico de métodos para el estudio del crimen organizado. De esa manera, Landesco seguía la tradición de la Escuela de Chicago, al desarrollar contactos extensos con grupos criminales de la ciudad.

Por su parte, el estudio de Giménez-Salinas, Requena y De La Corte, que sirvió de base o modelo para nuestro trabajo pero con una técnica investigativa distinta -revisión de expedientes policiales desde donde se obtuvieron datos de sujetos pertenecientes a organizaciones criminales- $-^{12}$, arrojó resultados interesantes, entre otros, que los miembros de las organizaciones criminales estudiadas tienen un media de edad de 33 años (31 para mujeres y 34 para hombres). En cuanto a la nacionalidad, la mayor representación corresponde a españoles (27\%), seguida de los que proceden de países miembros de la Unión Europea (18\%), especialmente nacidos en Rumania $(9,8 \%)$, seguido por Italia (1,4 $\%)$ y Polonia (1,3\%). Les sigue los nacidos en Europa pero no pertenecientes a la Unión Europea (15\%). A su vez, el $17 \%$ de los sujetos procede de países de América del Sur, destacando los colectivos de Colombia $(10,4 \%)$ y Venezuela $(3,5 \%)$; y el resto procede de países de América del Norte y Central (8\%), y de países asiáticos (1,5\%). En cuanto al mercado de ilícitos que estos sujetos pertenecientes a organizaciones criminales se dedican, cabe destacar el delito de robo con fuerza (25\%), seguido del tráfico de drogas (18\%), la receptación ( $8 \%$ ), el blanqueo de capitales y el tráfico de vehículos (5\% respectivamente). Los investigadores realizan una serie de correlaciones entre distintas variables, siendo importante destacar que la relación entre edad y posición jerárquica al interior de la organización no dista mucho de lo que ordena el sentido común, es decir, los sujetos de mayor edad ocupan los puestos de dirección y coordinación de la organización, mientras que los cargos intermedios y básicos están ocupados por los más jóvenes. Otra correlación interesante es la que dice relación con la nacionalidad del sujetos y la actividad ilícita de la organización, donde algunos datos arrojaron que los provenientes de América del Sur están más representados en el mercado del tráfico de drogas $(21,5 \%)$, la trata con fines de explotación sexual $(8,5 \%)$ y los delitos contra la propiedad (Hurtos con $41,8 \%$ y Robos con intimidación con un $22 \%$ ). En esta misma correlación, los sujetos provenientes de la UE $(71,5 \%)$ y los europeos no comunitarios $(50 \%)$ destacan en el robo con fuerza. También es importante poner de relieve el papel de la mujer, la que tiene un rol relevante en los delitos contra la propiedad, especialmente los hurtos, seguido de cerca por los robos

\footnotetext{
${ }^{11}$ LANDESCO, John, Organized crime in Chicago. $2^{\text {a }}$ Ed., Chicago: University of Chicago Press, 1969.

${ }^{12}$ La muestra general (1156 sujetos) se obtuvo a partir de 65 operaciones de crimen organizado desarrolladas por la Unidad Central Operativa (UCO) de la Guardia Civil y los Equipos de Crimen Organizado dependientes del departamento de delincuencia organizada de la UCO entre los años 1990 a 2010.
} 
SALINERO, Sebastián. "El crimen organizado en Chile. Una aproximación criminológica al perfil del delincuente a través de un estudio a una muestra no representativa de condenados por delitos de tráfico de estupefacientes".

con fuerza y robos violentos (cercana al $10 \%$ en total y el hurto es el delito más significativo). Le siguen las actividades relacionadas con el tráfico de drogas (cercana al 5 $\%)$. Los autores evidencian la relevante participación que tienen las mujeres en la trata de personas, específicamente con fines de explotación sexual, donde ocupa un papel preponderante al interior de la organización en labores de captación y control. Además enfatizan que la mujer se encuentra infra-representada en los puestos directivos o importantes de la organización con respecto a los hombres $(4,5 \%$ de las mujeres respecto de un $14,7 \%$ de los hombres) mientras que la diferencia es menos notable en puestos secundarios o básicos de la organización. Otro antecedente interesante que el estudio reportó, es el que dice relación con el estado civil, donde se estableció que el $92 \%$ de los sujetos están casados o conviven con una pareja. Igualmente el $95 \%$ tenían hijos. Un hallazgo importante, lo constituyó el hecho que el $77 \%$ de los sujetos tenían antecedentes policiales pretéritos. Finalmente, los autores destacan la imposibilidad de determinar un perfil socio-demográfico único del delincuente organizado y la necesidad de estudiar las trayectorias criminales ${ }^{13}$.

En el ámbito anglosajón, en el que sin lugar a duda los estudios criminológicos empíricos abundan por doquier, podemos destacar el trabajo de Francis y otros ${ }^{14}$, el cual en base a los antecedentes penales de los delincuentes que se involucran en el crimen organizado (muestra de 4.112 sujetos), en la gran mayoría por delitos relacionados con drogas, establecieron el perfil de estos criminales. Entre los hallazgos, podemos poner de relevancia que la edad promedio de los delincuentes organizados fue de 32 años. Esta edad es más vieja que la de los delincuentes en general, pero similar a la de los culpables de delitos graves. Sólo el $1 \%$ de los delincuentes del crimen organizado eran menores de 18 años al momento de cometer el delito de inclusión (ingreso al crimen organizado). También, casi todos los delincuentes del crimen organizado eran hombres (95\%), y el $13 \%$ por ciento fueron identificados como no nacionales del Reino Unido (una proporción ligeramente superior tanto para los delincuentes en general y de delitos graves). Otra conclusión importante es que los delincuentes organizados tenían más sanciones anteriores que los delincuentes en general. En promedio habían sido sancionados en nueve ocasiones antes de su inclusión en el crimen organizado. En lo que respecta a la especialización criminal, sólo el $12 \%$ fueron identificados como sujetos que se especializan en un tipo de delito antes de su inclusión en el crimen organizado. La mayoría de los que sí muestran signos de especialización habían recibido múltiples sanciones por delincuencia relacionada con las drogas.

En Chile, el Departamento Investigación de Organizaciones Criminales O.S. 9, Sección Análisis, realizó un estudio el año 2008, sobre pandillas juveniles. En su análisis, pudieron establecer la existencia de 137 pandillas que se encontraban operando en nuestro país e integrada por 1.745 jóvenes de distinto sexo. Además, concluyeron que el 89,78 \% de los

13 GIMÉNEZ-SALINAS, Andrea; REQUENA, Laura; DE LA CORTE, Laura, "¿Existe un perfil de delincuente organizado? Exploración a partir de una muestra española", Revista Electrónica de Ciencia Penal y Criminología, 13-3 (2011), pp. 1-32.

${ }^{14}$ FRANCIS, Brian; HUMPHREYS, Leslie; KIRBY, Stuart; SOOTHILL, Keith, "Understanding criminal careers in organized crime", Home Office, Reporte 74, Octubre 2013, pp. 1-120. 
Polít. crim. Vol. 10, № 19 (Julio 2015), Art. 2, pp. 25-55.

[http://www.politicacriminal.cl/Vol_10/n_19/Vol10N19A2.pdf]

grupos han presentado antecedentes relacionados con la comisión de algún tipo de delito; apreciándose que el de mayor frecuencia es el robo con intimidación con un 19,7 \% de los casos, seguido por las lesiones con un $13,14 \%{ }^{15}$.

Por otro lado, es interesante destacar las estadísticas de la Jefatura Nacional contra el Crimen Organizado de la Policía de Investigaciones de Chile (PDI), según las cuales en el período del año 2012, el total de delitos vinculados al crimen organizado a nivel nacional llegó a 475. De ellos, 154 correspondieron a delitos contra la propiedad (destaca el delito de Hurto con 41 incidentes); 127 son infracciones a la Ley de Drogas; 16 a la Ley sobre Propiedad Intelectual; y 4 a la Ley sobre Control de Armas. ${ }^{16}$

De acuerdo a cifras entregadas en el informe "Realidad nacional del crimen organizado transnacional", colgado en el portal de la Biblioteca del Congreso Nacional, el comportamiento criminal vinculado a bandas criminales experimentó un brusco aumento en el período 2007-2008, bajando en 2009 y volviendo a registrar una leve alza el 2010. En tanto, los ilícitos relacionados con organizaciones criminales mostraron un descenso en 2010, situación que la Policía Civil (PDI) explica a partir de dos hipótesis: la primera establece que la baja en la criminalidad se debería a un trabajo policial más efectivo, mientras la segunda sugiere que la detección de estas agrupaciones se habría vuelto más difícil, dada la complejidad de su modus operandi ${ }^{17}$.

Según el informe antes indicado, el primer semestre de 2011 la PDI desarticuló catorce bandas criminales ( $78 \%$ del total) y cuatro organizaciones criminales $(22 \%)$. A su vez, del total de delitos registrados en la categoría crimen organizado, el $61 \%$ correspondió a ilícitos vinculados con el tráfico de drogas. En términos geográficos, el informe de la PDI precisa que 74 de los integrantes de bandas y organizaciones criminales desbaratadas (86\% del total) tenían residencia en la Región Metropolitana, en tanto que solo seis vivían en la Región de Tarapacá y otros seis eran extranjeros sin residencia en el país ${ }^{18}$.

Otro aspecto que queríamos revisar en este aparatado, es el que dice relación con los problema que plantea la investigación del crimen organizado, el cual no dista mucho de los problemas que la investigación de la delincuencia genera desde cualquier perspectiva disciplinaria $^{19}$. Sin duda el crimen organizado es un fenómeno complejo de investigar, situación que ha sido dejada en evidencia por la Criminología, la cual ha manifestado la

15 Carabineros de Chile Dirección Investigación Delictual y Drogas Departamento Investigación de Organizaciones Criminales, "Situación actual de las pandillas juveniles en Chile", agosto, (2008). En http://ciperchile.cl/wp-content/uploads/informe-os9.pdf [fecha de visita el 30 de marzo de 2014].

\begin{tabular}{llllll}
\hline 16 & Estadísticas & Policía de & Investigaciones de Chile 2012.
\end{tabular} http://www.ine.cl/canales/menu/publicaciones/calendario_de_publicaciones/pdf/investigaciones_2012.pdf [fecha de visita el 30 de marzo de 2014].

17 Véase Informe Realidad Nacional del Crimen Organizado Transnacional, Biblioteca del Congreso Nacional, pp. 3 y ss.

18 Véase Informe Realidad Nacional del Crimen Organizado Transnacional, Biblioteca del Congreso Nacional, pp. 3 y ss.

19 Para un estudio en concreto de los problemas que genera desde el punto de vista metodológico las organizaciones criminales puede verse: ABADINSKY, Howard, Researching Organized Crime Methodological Problems, Cullowhee, NC: Western Carolina University, 1981. 
SALINERO, Sebastián. "El crimen organizado en Chile. Una aproximación criminológica al perfil del delincuente a través de un estudio a una muestra no representativa de condenados por delitos de tráfico de estupefacientes".

dificultad que existe para la medición de esta tipología delictiva ${ }^{20}$. En particular y concretizando los problemas al respecto, podemos decir que se presentan cuatro obstáculos en la investigación de este fenómeno. El primero relativo al concepto de crimen organizado, el cual generó un intenso debate en la década del noventa en torno a la definición y existencia del crimen organizado, alentado por posturas contrapuestas sobre la existencia y gravedad de este fenómeno, el cual sólo vino a superarse a inicios de este nuevo siglo, bajo la existencia de un consenso sobre la definición, proveniente desde el ámbito internacional, basada en un concepto claro desde el punto de vista criminológico. La segunda dificultad está referida a la medición de los denominados delitos complejos, cuyas formas de medición difieren de las acordadas para los delitos convencionales ${ }^{21}$. No es lo mismo medir un delito de homicidio que el crimen organizado, puesto que el primero constituye un acto singular y ejecutado individualmente y, en el segundo, la acción se realiza bajo la actuación de grupos criminales que desarrollan actividades ilícitas de las que obtienen los beneficios y que, para ello, necesitan de actividades instrumentales necesarias para el desarrollo de la actividad principal $^{22}$. El tercer problema para la investigación y relacionado con el anterior está referido a la disponibilidad y el acceso a los datos propios de esta tipología delictiva. Las fuentes oficiales, en el contexto internacional -y también en nuestro país-, no proveen de datos sobre este tipo de criminalidad ${ }^{23}$. Finalmente el último problema dice relación con que se trata de un delito transnacional ${ }^{24}$, el que por esta característica también dificulta la medición de mismo, ya que por ejemplo una célula o ramificación de la organización en un determinado lugar no nos aporta información sobre el volumen correspondiente a toda la organización desde un punto de vista global y además para su medición supone la intervención de diversos actores (países) lo que de suyo también es difícil.

También a propósito de los problemas de investigación, en nuestro estudio pudimos advertir las dificultades en el acceso a fuentes fiables para el estudio del fenómeno y, más aún, cuando estas fuentes son los propios participes de estas organizaciones. Saber si la información entregada por los encuestados a los entrevistadores es veraz, es una realidad que desconocemos y que menos aún podemos asegurar. Sin embargo, estamos contestes y compartimos que de existir margen de error, el que seguramente hay, no es en su límite

\footnotetext{
${ }^{20}$ GIMÉNEZ-SALINAS, El crimen, cit. nota n ${ }^{\circ}$ 5, pp. 13 y ss.

21 VAN DIJK, Jan, "Mafia markers: assessing organized crime its impact upon societies", Trends in Organized Crime, $\mathrm{N}^{\circ} 10$ (2007), pp. 39-56, pp. 40 y ss.

${ }^{22}$ GIMÉNEZ-SALINAS, Andrea; DE LA CORTE, Luis; REQUENA, Laura; DE JUAN, Manuel, "La medición y evaluación de la criminalidad organizada en España: ¿Misión imposible?”, Revista Española de Investigación Criminológica, $\mathrm{N}^{\mathrm{o}} 9$ (2009), pp. 1-28. Entre otras cosas, los autores profundizan en los conceptos de actividades principales y secundarias, y destacan tres dimensiones esenciales para medir la criminalidad organizada: grupos, mercados y actividades instrumentales.

${ }^{23}$ VAN DIJK, Jan; NEVALA, Sami, "Results of an analysis of the correlations between indices of different types of conventional and non-conventional crime", en: NIEUWBEERTA, P. (Ed.), Crime victimization in international perspective: results from the international crime victims survey, 1989-2000. Den Haag: Boom Juridische Uitgevers, 2002, pp. 183-193.

${ }^{24}$ Delito transnacional se define como crímenes o delitos cuya creación, prevención, y/o efectos directos o indirectos implican a más de un país. MUELLER, Gerhard, "Transnational crime: Definitions and concepts”, en: WILlIAMS, Phil; VLASSIS, Dimitri (Eds.) Combating transnational crime. Concepts, activities and responses, Londres: Frank Cass, 2001, p.13.
} 
Polít. crim. Vol. 10, No 19 (Julio 2015), Art. 2, pp. 25-55.

[http://www.politicacriminal.cl/Vol_10/n_19/Vol10N19A2.pdf]

inferior, sino superior. Esto quiere decir, que estimamos que frente a los resultados presentados, las personas que pudiesen efectivamente pertenecer a una organización criminal podrían ser más de las que afirmativamente así lo declararon. Esta apreciación se basa en la creencia de los encuestadores por el grado de conocimiento personal y previo que tenían de los entrevistados.

\section{Explicación criminológica del crimen organizado.}

La Criminología como ciencia interdisciplinaria se ha ocupado de la etiología del delito. Así, en sus distintas disciplinas, como la de corte biológico, psicológico -también psiquiátrico-, y sociológico han pretendido con mayor o menor éxito explicar el delito y la conducta desviada. En particular, la Criminología sociológica, a la que acudiremos, ofrece una serie de teorías para explicar el crimen y el comportamiento criminal. Sin embargo, raramente existe algún modelo teórico que esté dirigido especialmente a explicar el crimen organizado. Eso sí, algunas teorías como las que revisaremos a continuación, proporcionan información sobre la delincuencia organizada que es importante tener en consideración. Advertimos eso si, que la revisión que realizaremos a continuación no es exhaustiva, sino meramente ejemplificadora de éste fenómeno criminal asociativo ${ }^{25}$. La agudeza que este tema requiere para su tratamiento en profundidad, nos privaría del real contenido de este trabajo que no es otro que mostrar la información descriptiva recabada de un estudio de campo.

Comenzando, podemos señalar que para Merton, en su conocida teoría sobre la anomia, el crimen organizado es una respuesta normal a las presiones ejercidas sobre ciertas personas por la estructura social de la tensión entre los objetivos (económicos, estatus, etc.) y medios para conseguirlos ${ }^{26}$.

Como es conocido, Merton afirma que hay cinco modos de adaptación individual a este fenómeno: conformidad, ritualismo, rebelión, retraimiento e innovación. ${ }^{27}$ Sólo con la última adaptación -innovación- se puede incluir la actividad criminal organizada. Puesto, que si bien el sujeto acepta los fines sociales convencionales y rechaza los medios socialmente reconocidos para su consecución, busca nuevos medios o instrumentos para el logro de sus metas, siendo la delincuencia organizada un medio posible para alcanzar esas metas.

Por su parte, Sutherland con su teoría sobre la Asociación diferencial reseñaba la utilización del aprendizaje como explicación de la delincuencia asociativa. El delincuente no nace, sino que se hace así por aprendizaje. La conducta criminal se aprende en la intimidad de los grupos o asociaciones y depende de la intensidad, frecuencia, prioridad y duración de la interacción social en el seno de la asociación criminal. El grupo criminal ofrece un aprendizaje tanto de las técnicas y habilidades delictivas necesarias para realizar la

\footnotetext{
${ }^{25}$ Una buena recopilación puede verse en: GIMÉNEZ-SALINAS; Para profundizar véase: ABADINSKY, Howard, Organized crime, $10^{\mathrm{a}}$ Ed., Belmont: Wadworth, 2013.

${ }^{26}$ ABADINSKY, Organized crime, cit. nota n ${ }^{\circ} 25$, pp. 80 y ss.

27 Para una explicación más acabada véase: VOLD, George; BERNARD, Thomas; SNIPES, Jeffrey, Theoretical Criminology, $5^{\text {a }}$ Ed., New York: Oxford University Press, 2002, pp. 138 y ss.
} 
SALINERO, Sebastián. "El crimen organizado en Chile. Una aproximación criminológica al perfil del delincuente a través de un estudio a una muestra no representativa de condenados por delitos de tráfico de estupefacientes".

actividad criminal, como también ofrece un aprendizaje sobre la racionalización o neutralización de la conducta delictiva (justificantes de la actividad criminal), mediante la incorporación de definiciones favorables hacia la actividad delictiva ${ }^{28}$.

Por otra parte, la Escuela de Chicago y en particular los postulados de Shaw y McKay sobre la denominada desorganización social explican que la criminalidad tiene un compuesto de origen ambiental, es decir, la criminalidad tiene base alrededor de un barrio específico, sin importar quién viva en él en determinado momento. Una vez que la criminalidad se convierte en parte de la cultura de la zona, se convierte en una tradición que se transmite de generación en generación (contagio). Por lo tanto es el lugar y no la gente lo que importa o lo que tiene sentido para explicar el delito ${ }^{29}$.

Como indica Giménez-Salinas, si adaptamos estas condiciones a la explicación de la delincuencia organizada, tendremos como resultado que en lugares o contextos sociales caracterizados por la desorganización social, la falta de control familiar, comunitario y formal, y la existencia de una tradición de delincuencia organizada desarrollada, se creará una subcultura favorable a dicha delincuencia que hará más probable que un joven nacido en dicho barrio tenga una mayor exposición a la criminalidad de estos grupos y pueda ser reclutado o atraído por ellos. En estos lugares, los grupos criminales gozan de una buena reputación, están bien integrados en la comunidad y existe una subcultura proclive a considerar el crimen organizado como una vía legítima para la obtención de logros ${ }^{30}$.

Otra teoría es la de Cloward y Ohlin, sobre la oportunidad diferencial, tratada en su obra Delinquency and Opportunity: The Theory of Delinquent Gangs, que viene a integrar las teorías criminológicas más importantes de la década del 60 (la anomia de Merton, la asociación diferencial de Sutherland y la de la subcultura de Cohen) ${ }^{31}$ y nos ofrece una respuesta al proceso a partir del cual muchos jóvenes se incorporan a grupos delictivos, al ver que los objetivos sociales son inalcanzables por medios legítimos y no son accesibles para todos los ciudadanos en condiciones de igualdad. En definitiva, será delincuente según esta teoría, no ya sólo el que tenga vedado el acceso a las metas del triunfo social por medios legítimos, sino también el que no puede o no tiene las oportunidades de llegar a serlo.

La teoría de la sucesión étnica es diferente de las demás, ya que explica la movilidad social, el por qué algunos grupos de personas comienzan en el crimen organizado y luego se trasladan a proyectos empresariales legítimos. Esta teoría ve la delincuencia como medio para alcanzar un fin, y, una vez alcanzado, se abandona la delincuencia. La participación de los judíos en el crimen organizado en Estados Unidos es un gran ejemplo de esto. El pueblo judío valora la educación y la religión como los objetivos más importantes a seguir.

\footnotetext{
${ }^{28}$ SUTHERLAND, Edwin; CRESSEY, Donald, Principles of criminology, $10^{\mathrm{a}}$ Ed., Philadelphia: Lippincott, 1978 , pp. 80 y ss.; VOLD/BERNARD/SNIPES, Theoretical Criminology, cit. nota ${ }^{\circ} 27$, pp. 159 y ss.

${ }^{29}$ VOLD/BERNARD/SNIPES, Theoretical Criminology, cit. nota n ${ }^{\circ} 27$, pp. 121 y ss.

${ }^{30}$ GIMÉNEZ-SALINAS, El crimen, cit. nota n ${ }^{\circ}$ 5, p. 29.

${ }^{31}$ HASSEMER, Winfried; MUÑOZ CONDE, Francisco, Introducción a la Criminología, Valencia: Tirant lo Blanch, 2001, pp. 120 y ss.
} 
Polít. crim. Vol. 10, № 19 (Julio 2015), Art. 2, pp. 25-55.

[http://www.politicacriminal.cl/Vol_10/n_19/Vol10N19A2.pdf]

Mientras que comenzaron en el crimen organizado con el fin de lograr una movilidad social ascendente, las personas dispuestas a cometer delitos por el dinero fácil se desvanecieron una vez que lograron caminos legítimos para el éxito ${ }^{32}$. Esta teoría se inspira, por un lado, en el marco conceptual proporcionado por la teoría de la oportunidad diferencial, para adaptarlo a un colectivo especialmente huérfano de oportunidades legales como son los inmigrantes, y, por otro, en el marco teórico de Daniel Bell ${ }^{33}$, el cual otorgó a las organizaciones criminales una funcionalidad social en los Estados Unidos de mediados del siglo pasado $^{34}$.

Una de las teorías más ampliamente reconocidas sobre el crimen organizado hoy en día y relacionada de alguna manera con la anterior, se conoce como la teoría de la conspiración alienígena. Esta teoría culpa a los extranjeros y las influencias externas de la prevalencia de la delincuencia organizada en la sociedad norteamericana. La teoría de la conspiración alienígena postula que el crimen organizado, particularmente la mafia, ganó notoriedad durante la década de 1860 en Sicilia y que los inmigrantes sicilianos son los responsables del establecimiento en EE.UU. de las bases de la delincuencia organizada. Estos grupos ocupan zonas geográficas específicas, las cuales controlan, para su negocio criminal $^{35}$.

La etnia es una clave para la teoría de la conspiración alienígena del fenómeno del crimen organizado. Muchos criminólogos sostienen, sin embargo, que la investigación empírica disponible indica que esta teoría interpreta mal y exagera el papel de la etnicidad en el crimen organizado. Por ello algunos escépticos han indicado que más bien responde a exacerbaciones de los medios de comunicación. Alguna evidencia sugiere que muchos grupos del crimen organizado se componen de personas de un origen étnico específico que cooperan en forma regular ${ }^{36}$, pero el estudio de Haller deja en claro que los criminales organizados que desean sobrevivir y prosperar aprenden rápidamente los límites del parentesco, la etnicidad y la violencia y proceden a formar asociaciones lucrativas sobre la base de las decisiones empresariales racionales y necesidades comunes ${ }^{37}$. Sin embargo, como advierte Lyman y Protter $^{38}$, existe una aparente contradicción de la teoría de la conspiración alienígena dada por el simple hecho de que casi todas las ciudades EE.UU. tenía los sindicatos del crimen organizado bien desarrolladas mucho antes de la inmigración italiana a gran escala de finales de los siglos XIX y XX. De esta manera, los foráneos itálicos contribuyeron no a la formación de esta tipología delictiva, sino a acentuar el ya existente y nativo crimen organizado.

\footnotetext{
${ }^{32}$ ABADINSKY, Organized crime, cit. nota ${ }^{\circ} 25$, p. 89.

33 Sociólogo estadounidense que destacó por su intuición para detectar importantes cambios sociales en la segunda mitad del siglo pasado. Véase "El advenimiento de la sociedad post-industrial".

${ }^{34}$ GIMÉNEZ-SALINAS, El crimen, cit. nota n ${ }^{\circ}$ 5, p 31.

${ }^{35}$ LYMAN, Michael; POTTER, Gary, Organized Crime. $4^{\mathrm{a}}$ Ed., New Jersey: Prentice Hall, 2007, p. 60.

36 BLOCK, Richard, "Community, environment and violent crime", Criminology, 17 (1979), pp. 46-57; POTTER, Gary; JENKINS, Philip, The City and the Syndicate: Organizing Crime in Philadelphia. Lexington, MA: Ginn Press, 1985.

${ }^{37}$ HALLER, Mark, "Illegal Enterprise: A theoretical and historical interpretation”, Criminology, 28 (1990), pp. 207-236.

${ }^{38}$ LYMAN/POTTER, Organized Crime, cit. nota $n^{\circ}$ 35, p. 61.
} 
SALINERO, Sebastián. "El crimen organizado en Chile. Una aproximación criminológica al perfil del delincuente a través de un estudio a una muestra no representativa de condenados por delitos de tráfico de estupefacientes".

\section{El estudio empírico: Objetivos y metodología.}

Los objetivos del estudio los podríamos circunscribir a los siguientes: a) Determinar cuántos sujetos de la muestra encuestada pertenecerían a una organización criminal; b) Conocer las características socio-demográficas de los sujetos que declararon afirmativamente su pertenencia; c) Descubrir algunas características de la organización criminal a partir de los datos aportados por los encuestados, tales como: estructura jerárquica o rol desempeñado por el encuestado, tiempo de permanencia y negocios o actividades ilícitas a la cuales se dedica la organización; y d) Establecer la necesidad de realizar nuevos estudios cualitativos y cuantitativos tendientes a una mayor exploración del fenómeno.

El método utilizado en esta investigación ha sido el propio de la Criminología empírica, en particular una metodología cuantitativa basada en una encuesta estructurada con preguntas cerradas realizadas a una muestra $(\mathrm{N}=200)$ no representativa estadísticamente de condenados por narcotráfico que purgan una pena privativa de libertad. La selección de estos delitos en particular, obedeció a la necesidad de descubrir una organización criminal a través de los ilícitos que comúnmente este tipo de entidades comete, siendo esta tipología delictiva de aquellas que por antonomasia caracterizan al crimen organizado y así lo ha indicado la literatura especializada ${ }^{39}$. La aplicación de la encuesta se realizó de manera personal a los condenados, su ejecución estuvo a cargo de personas del área de las ciencias sociales, específicamente por Trabajadores Sociales, que tenían la especial característica de haber tenido más de un encuentro con los encuestados de manera previa a la realización de la encuesta ${ }^{40}$. El cuestionario utilizado estaba compuesto de un total de 16 preguntas ${ }^{41}$, empero, una pregunta fue eliminada para su análisis por la eventualidad que ella podía generar equívocos en sus respuestas ${ }^{42}$. En cuanto a su estructura y contenido, las preguntas son de creación propia y no se trata de ningún instrumento homologado a nuestra realidad con su validación respectiva-, por lo que es necesario hacer presente los riesgos de validez que ello supone.

\footnotetext{
${ }^{39}$ ABADINSKY, Organized crime, cit. nota ${ }^{\circ} 25$, pp. 277 y ss.; ALBANESE, Jay, Organized Crime in Our

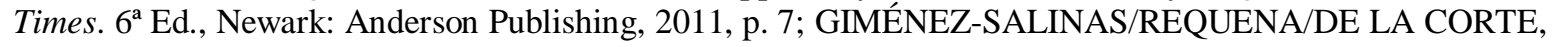
“Existe un perfil”, cit. nota ${ }^{\circ}{ }^{\circ} 13$, p.11. En este estudio se establece que el tráfico de drogas es el segundo mercado en la distribución de ilícitos que interesa a la criminalidad organizada.

${ }^{40}$ La encuesta fue ejecutada de manera personal por los trabajadores sociales doña María Teresa Berríos P., doña Jessica Morales M. y don José Ramos V., a quienes agradecemos su participación y colaboración en este proyecto.

${ }^{41}$ Véase Anexo 1.

${ }^{42}$ La pregunta 9) del cuestionario estaba redactada de la siguiente forma: “¿Qué opina del nivel de ingresos de su hogar?". A su vez, ofrecía las siguientes alternativas de respuesta: "Satisfecho/Bastante satisfecho/Insatisfecho/Muy insatisfecho". En la discusión de resultados se pudo percibir que la pregunta y sus posibles respuestas generaban equívocos en los entrevistados, en particular que algunos de ellos entendían la percepción de ingresos en momentos distintos lo que claramente podía distorsionar los resultados. Algunos encuestados respondían la pregunta pensando sus ingresos al momento de la comisión del delito por el cual fueron condenados y que, en definitiva, operó como móvil para su comisión; y otros, en cambio, comprendieron la pregunta al tiempo de su reclusión, es decir, al momento que se encontraban purgando su pena privativa de libertad.
} 
Polít. crim. Vol. 10, № 19 (Julio 2015), Art. 2, pp. 25-55.

[http://www.politicacriminal.cl/Vol_10/n_19/Vol10N19A2.pdf]

En cuanto a la población y muestra, el universo de esta investigación está formado por nacionales y extranjeros -de manera legal o no-, de 18 años o más, que se encuentren cumpliendo una pena privativa de libertad.

La muestra se extrajo de las personas que estaban condenada por alguno de los delitos de la Ley de Drogas -específicamente el delito de tráfico de estupefacientes en grandes o pequeñas cantidades-, en los Centros de Cumplimiento Penal de Colina I y II, y el Centro Penitenciario Femenino, todos de la Región Metropolitana. Si bien, pudiese ser cuestionable desde el punto de vista metodológico la forma de selección del los centros penitenciarios, esta elección obedeció a las facilidades que entrega la cercanía territorial y también porque los encuestadores ya eran conocidos en esos recintos penitenciarios, generando eventuales confianzas en los encuestados y, de esta manera, lograr tasas de respuesta en las mismas. Además debemos recordar, que este es un estudio exploratorio y descriptivo, por lo que una de sus misiones es encontrar temas o ciertos tópicos para ser abordados en futuras investigaciones.

La amplitud de la muestra invitada fue de 200 personas, distribuida en igual número de hombres y mujeres. Esta distribución no está estratificada ya que, como se ha dicho, lo que se buscaba era una aproximación descriptiva y exploratoria. Así la relevancia que la muestra sea representativa es de segundo plano y sólo interesa características que se repiten en cada encuestado en forma sistemática. Lo que es importante para nuestro estudio, es la calidad de la muestra, es decir, que refleje realidades ampliables. Esto implica que las personas encuestadas son homogéneas, o sea, que sacando o extrayendo una unidad son todos iguales.

Las encuestas se realizaron entre los meses de septiembre y octubre de 2013.

Como se dijo, el concepto utilizado de organización criminal es el que se estableció en la Convención de Palermo, que entiende por ella: "un grupo estructurado de tres o más personas que existe durante cierto tiempo y que actúa concertadamente con el propósito de cometer uno o más delitos graves, con miras a obtener, directa o indirectamente, un beneficio económico u otro beneficio de orden material". Este concepto fue el explicitado a los encuestados, previo a la ejecución de la encuesta. Ahora bien, se eligió este concepto por sobre el criminológico antes propuesto, pues éste podrá permitir no sólo el reconocimiento transversal de un mismo término, sino también, y a pesar de no ser nuestro objetivo en estos momentos, ayudaría en el estudio comparado de similitudes y diferencias del mismo fenómeno social delictivo en otras realidades internacionales.

Finalmente, y a modo de recapitulación general, el estudio fue desarrollado en cuatro etapas: a) en la primera se determinó la naturaleza del estudio y la necesidad de aplicar una encuesta con un número reducido de preguntas y cerrado de respuestas, con el principal objetivo de conseguir características del condenado participante del crimen organizado; b) en la segunda etapa se confeccionó el cuestionario y plantilla de recogida de datos; c) completado el cuestionario se ejecutaron las encuestas por parte de los trabajadores sociales, quienes, a su vez, bajaron los datos obtenidos para generar los resultados globales; 
SALINERO, Sebastián. "El crimen organizado en Chile. Una aproximación criminológica al perfil del delincuente a través de un estudio a una muestra no representativa de condenados por delitos de tráfico de estupefacientes".

d) para terminar se realizó la discusión entre todos los participes y se confeccionó el informe que ahora se presenta.

\section{Resultados obtenidos.}

Previamente debemos destacar las facilidades y buena disposición entregada por las personas encuestadas. Si bien las condiciones del lugar (encierro) no eran las óptimas para practicar una encuesta porque no existía un marco de relajo y se percibía inseguridad por parte del entrevistado - pese al conocimiento previo de la pareja interlocutora-, fundado presuntamente en que se entregaba información que podía acarrear una nueva responsabilidad criminal o la delación de terceros intervinientes en un delito, podemos señalar que es nuestra creencia que las respuesta obtenidas fueron cercanas a la verdad $\mathrm{y}$, de existir algún cuestionamiento de veracidad, éste vendría dado por haber existido mucho más personas de la muestra pertenecientes a una organización criminal, respecto de las que efectivamente así lo declararon.

\subsection{Muestra.}

La muestra aleatoriamente seleccionada corresponde a 200 personas, siendo su composición de género equitativa, la mitad fueron hombres y la parte restante mujeres. En cuanto a sus características por edad, nacionalidad, estado civil y ocupación, éstas se especifican en las tablas siguientes:

\begin{tabular}{|c|c|}
\hline \multicolumn{2}{|c|}{ Género } \\
\hline Hombres & Mujeres \\
\hline 100 & 100 \\
\hline
\end{tabular}

\begin{tabular}{|c|c|c|c|}
\hline \multicolumn{4}{|c|}{ Edad } \\
\hline & Hombres & Mujeres & Índice \\
\hline 18 - 25 años & 4 & 20 & $12 \%$ \\
\hline 26-32 años & 17 & 21 & $19 \%$ \\
\hline 33 - 40 años & 28 & 29 & $28,5 \%$ \\
\hline $41-50$ años & 36 & 18 & $27 \%$ \\
\hline 51 - 60 años & 11 & 10 & $10,5 \%$ \\
\hline más de 60 años & 4 & 2 & $3 \%$ \\
\hline
\end{tabular}

\begin{tabular}{|c|c|}
\hline \multicolumn{2}{|c|}{ Nacionalidad } \\
\hline Chileno & Extranjero \\
\hline 177 & 23 \\
\hline
\end{tabular}


Polít. crim. Vol. 10, No 19 (Julio 2015), Art. 2, pp. 25-55.

[http://www.politicacriminal.cl/Vol_10/n_19/Vol10N19A2.pdf]

\begin{tabular}{|c|c|c|c|}
\hline \multicolumn{4}{|c|}{ Estado civil } \\
\hline & Hombres & Mujeres & $\%$ \\
\hline Casado & 39 & 21 & 30 \\
\hline Convive & 25 & 37 & 31 \\
\hline Separado & 3 & 33 & 18 \\
\hline Soltero & 29 & 9 & 19 \\
\hline Viudo & 4 & 0 & 2 \\
\hline
\end{tabular}

\begin{tabular}{|c|c|}
\hline \multicolumn{2}{|c|}{ Ocupación } \\
\hline Profesional & No profesional \\
\hline 6 & 194 \\
\hline
\end{tabular}

\subsection{Pertenencia a una organización criminal.}

Del total de la muestra, el $35 \%$ (n 70) declaro pertenecer a una organización criminal cuando cometió el delito por el cual fue condenado.

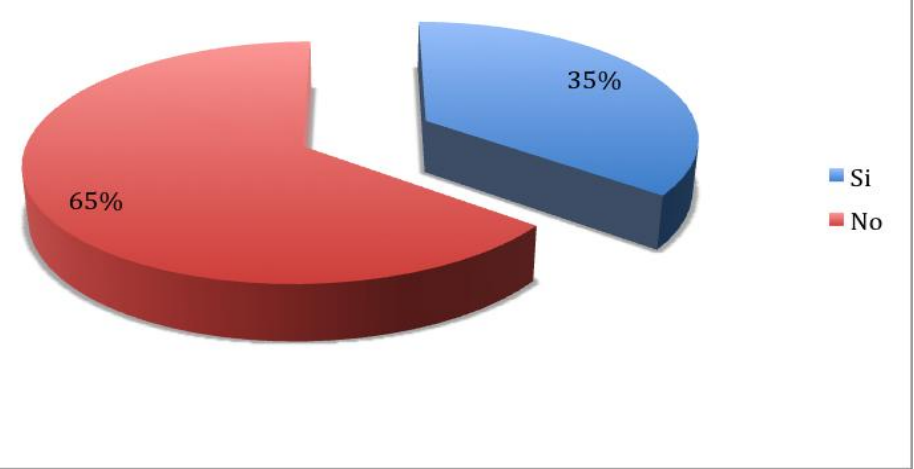

Gráfico 1. Pertenencia a una organización criminal

En su distribución por género los resultados fueron similares, pero con un leve predominio femenino. Las mujeres que declararon pertenecer a una organización criminal alcanzaron el $51 \%$ (36) y, en cambio, los hombres el $49 \%$ (35). Con ello, se relativiza la histórica dominación que el género masculino venia presentando en estos delitos organizativos y que diversos estudios venían exhibiendo resultados sorprendentes al respecto ${ }^{43}$.

\subsection{Edad de los sujetos.}

La variable edad de los sujetos enfrentada al género, es algo importante de destacar. Mientras en las mujeres, la distribución etárea es una tema bastante homogéneo en las primeras cuatro escalas medidas (18-60 años), destaca una mayor presencia en relación a

${ }^{43}$ ALBANESE, Organized Crime in Our Times, cit. nota n 39, p. 14.; GIMÉNEZ-SALINAS/REQUENA/ DE LA CORTE, “¿Existe un perfil”, cit. nota ${ }^{\circ}{ }^{\circ} 13$, p.11. El género masculino dominó ampliamente la escena del crimen organizado con un $83 \%$. 
SALINERO, Sebastián. "El crimen organizado en Chile. Una aproximación criminológica al perfil del delincuente a través de un estudio a una muestra no representativa de condenados por delitos de tráfico de estupefacientes".

los hombres en la parte inferior de la escala. Así, el $50 \%$ de las mujeres que declararon pertenecer a una organización criminal se sitúa entre los 18 y 32 años, en cambio, en los hombres, en el mismo tramo, su presencia alcanza al $23 \%$. Sin duda, la principal característica que presenta el género masculino que confesó pertenecer a una organización criminal, dice relación con que el $63 \%$ se encuentra en el tramo comprendido entre los 33 y 50 años. Esto guardaría relación con otros estudios científicos, donde la cualidad de tratarse de delincuentes mayores de 30 años marca una característica de las organizaciones criminales $^{44}$.

\begin{tabular}{|c|c|c|}
\hline Edad & Mujeres & Hombres \\
\hline $18-25$ & $27,7 \%$ & $8,6 \%$ \\
\hline $26-32$ & $22,3 \%$ & $14,3 \%$ \\
\hline $33-40$ & $27,7 \%$ & $25,7 \%$ \\
\hline $41-50$ & $22,3 \%$ & $37,1 \%$ \\
\hline $51-60$ & - & $8,6 \%$ \\
\hline más de 60 & - & $5,7 \%$ \\
\hline
\end{tabular}

Tabla 1. Distribución etárea

\subsection{Nacionalidad de los miembros.}

Una variable importante de destacar es la que dice relación con la nacionalidad, la que de cierta manera garantiza la transnacionalidad del fenómeno delictivo que es objeto de estudio. En la muestra analizada, el total de extranjeros alcanzó a 23 personas y, de ellas, unas 22, que corresponden a algo más del $95 \%$ del total de foráneos, contestó afirmativamente pertenecer a una organización criminal. A su vez, si realizamos una comparación entre los chilenos y extranjeros que aceptaron su pertenencia a esta tipo de entidad asociativa, advertimos que los primeros ascienden al $69 \%$ y los segundos al 31 $\%$.

\footnotetext{
${ }^{44}$ KLEEMANS, Edward R.; DE POOT, Christianne J., "Criminal Careers in Organized Crime and Social Opportunity Structure", European Journal of Criminology, Vol. 5, $\mathrm{N}^{\circ} 1$ (2008), pp. 69-98, p. 74. En este estudio, el $76 \%$ de la muestra censada se encuentra en el grupo etáreo superior a los 30 años de edad; GIMÉNEZ-SALINAS/REQUENA/DE LA CORTE “¿Existe un perfil”, cit. nota ${ }^{\circ}$ 13, p.11. El estudio estableció que la media de edad fue de 33 años tanto para hombres como para mujeres.

${ }^{45}$ En el estudio de Giménez-Salinas y otros el 55\% de la muestra que señaló pertenecer a una organización criminal era de origen extranjero (incluido los no comunitarios). GIMÉNEZ-SALINAS/REQUENA/DE LA CORTE, “Existe un perfil”, cit. nota n 13, p.12.
} 
Polít. crim. Vol. 10, № 19 (Julio 2015), Art. 2, pp. 25-55.

[http://www.politicacriminal.cl/Vol_10/n_19/Vol10N19A2.pdf]

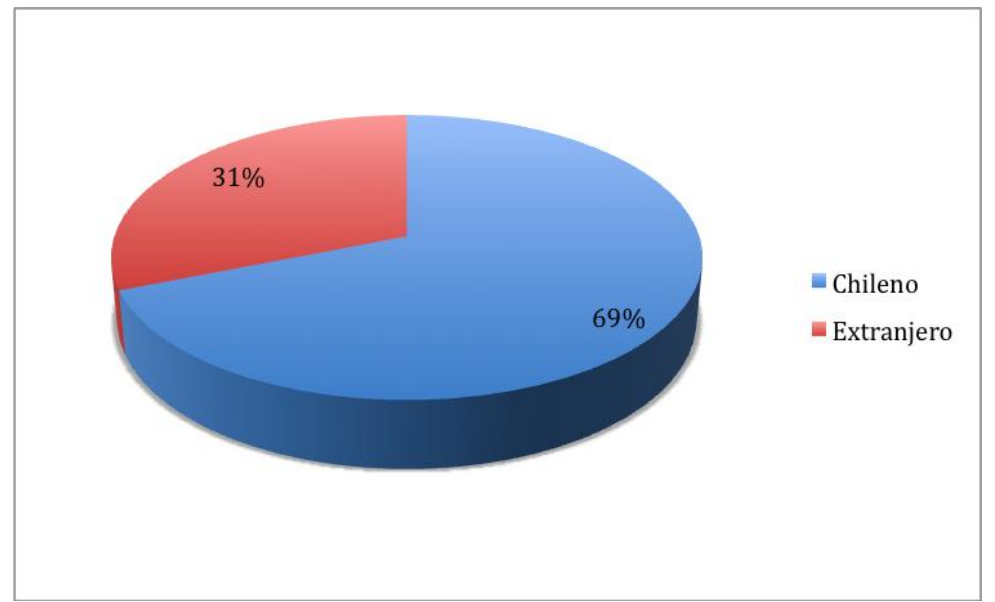

Gráfico 2. Nacionalidad

A lo anterior, se suman dos situaciones interesantes de destacar. La primera, es el patente predominio del género femenino $(76 \%)$ en la presencia de foráneos que declaró pertenecer a una organización criminal y, lo segundo, es que el $67 \%$ de estos extranjeros indicó haber ingresado de manera ilegal al país ${ }^{46}$.

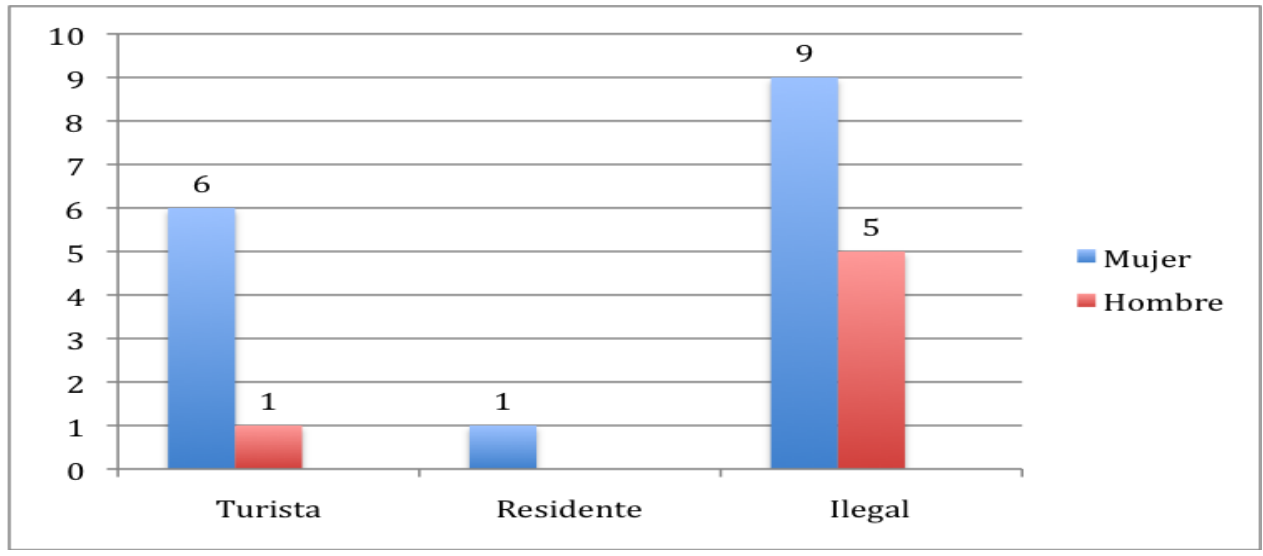

Gráfico 3. Extranjeros por género y modalidad de ingreso al país

\subsection{Estado civil y composición del grupo familiar.}

Para algunas teorías criminológicas, el estado civil y particularmente el matrimonio o la existencia de una pareja en general tienen efectos protectores y ralentizadores de la carrera delictiva, de ahí la consideración de esta variable en nuestro estudio ${ }^{47}$. Variable que en particular aportó datos interesantes, como que el grupo de mujeres pertenecientes a una organización criminal, el $50 \%$ señaló ostentar la condición de soltera; seguida por el $31 \%$

\footnotetext{
${ }^{46}$ Cuando hablamos de ingreso ilegal al país nos referimos al ingreso fraudulento y clandestino previsto en los artículos 68 y 69 del Decreto Ley $\mathrm{N}^{\circ}$ 1094, de 14 de julio de 1975, que establece normas sobre extranjeros en Chile.

${ }^{47}$ SAMPSON, Robert; LAUB, John, Crime in the Making: Pathways and turning points through life. Cambridge: Harvard University Press, 1993, pp. 101 y ss.; FARRINGTON, David, "The explanation and prevention of youthful offending" en: CORDELLA, Peter; SIEGEL, Larry (Eds.), Readings in Contemporary Criminological Theory. Boston: Northeastern University Press, 1996, p. 264.
} 
SALINERO, Sebastián. "El crimen organizado en Chile. Una aproximación criminológica al perfil del delincuente a través de un estudio a una muestra no representativa de condenados por delitos de tráfico de estupefacientes".

que indicó estar en relación de convivencia y finalmente el $19 \%$ dijo estar casada. En los hombres, en cambio, la mayoría ascendente al $45 \%$ reconoció ser casado, luego le sigue el $26 \%$ que declaro ser soltero, el $23 \%$ estar en relación de convivencia y, para terminar, el 6 $\%$ se confesó viudo ${ }^{48}$.

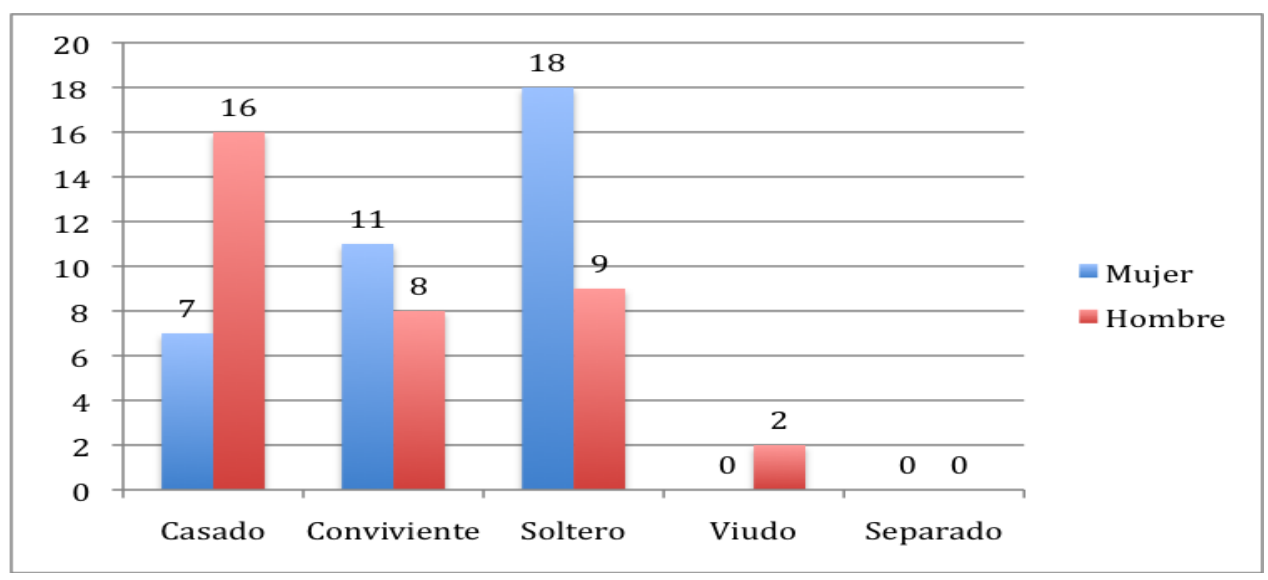

Gráfico 4. Estado civil

En lo que respecta a la paternidad de los involucrados, el $82 \%$ reconoció ser padre o madre y el restante $18 \%$ negó esa condición.

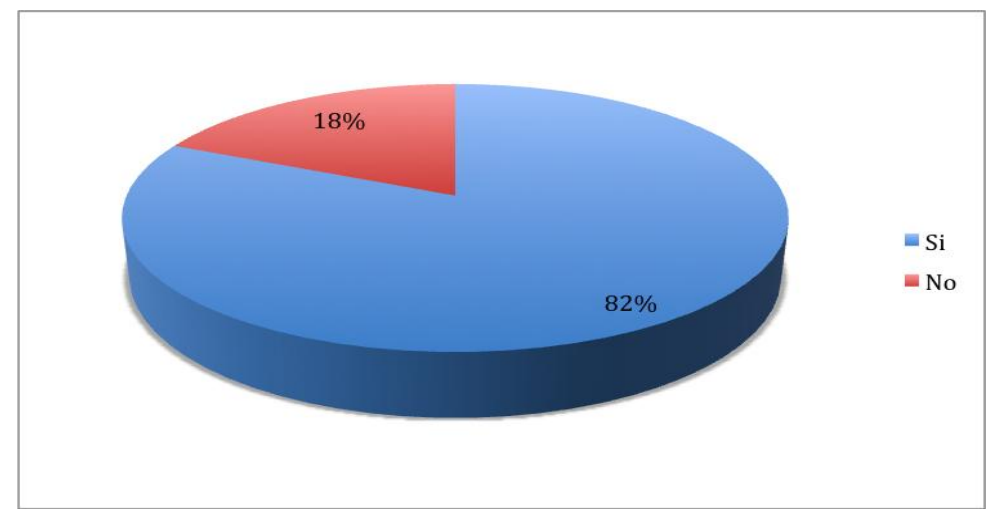

Gráfico 5. Paternidad

En cuanto a la composición del grupo familiar, la mayoría de los entrevistados (54\%) indicó tener un grupo familiar de entre 2 y 4 personas, siguiéndoles los que declararon pertenecer a un grupo de más de 5 personas (46\%).

\footnotetext{
${ }^{48}$ El estudio de Giménez-Salinas y otros nos ofrece información sobre estado civil y delincuencia organizada, siendo sus resultados más importantes los siguientes: el 41,2 \% de la muestra declaró estar casado; 35,2\% en relación de convivencia; el 15,3\% señaló tener pareja (sin convivencia); el $4 \%$ ser soltero y divorciado respectivamente; y el 0,3\% dijo ser viudo. GIMÉNEZ-SALINAS/REQUENA/DE LA CORTE, “Existe un perfil”, cit. nota ${ }^{\circ} 13$, p. 17 .
} 
Polít. crim. Vol. 10, № 19 (Julio 2015), Art. 2, pp. 25-55.

[http://www.politicacriminal.cl/Vol_10/n_19/Vol10N19A2.pdf]

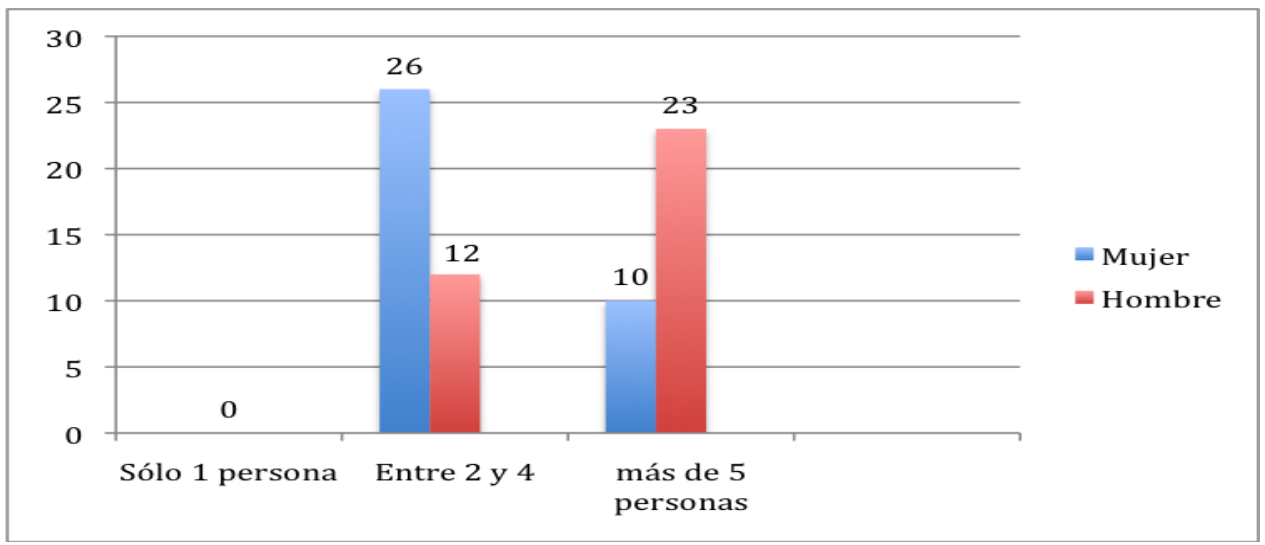

Gráfico 6. Composición del grupo familiar

\subsection{Ocupación y profesionalización.}

La importancia de tener un empleo u ocupación es un factor inhibidor de la conducta delictiva. Así ha quedado de manifiesto por algunos criminólogos que correlacionan esta variable con la delincuencia ${ }^{49}$.

En nuestro estudio, en el marco de una actividad laboral tanto para hombres como para mujeres destaca que el $56 \%$ señaló dedicarse únicamente a un quehacer ilegal. A ese respecto, existe un claro predominio de las mujeres (69\%) por sobre los hombres (43\%). Seguidamente, le siguen los que declararon que sin perjuicio de pertenecer a una organización criminal realizan un trabajo legal (24\%); y finalmente los desempleados que alcanzaron el $18 \%$ del total de la muestra ${ }^{50}$.

\footnotetext{
${ }^{49}$ Puede verse un resumen de estos estudios en VOLD/BERNARD/SNIPES, Theoretical, cit. nota $\mathrm{n}^{\circ} 27, \mathrm{pp}$. 84 y ss.

${ }^{50}$ En Giménez-Salinas y otros se detectó que el $31 \%$ de la muestra tenía un trabajo legal, el $3 \%$ se encontraba desempleado y el $66 \%$ hacía del delito su medio de subsistencia. GIMÉNEZ-SALINAS/ REQUENA/DE LA CORTE, “¿Existe un perfil”, cit. nota n 13, p. 20.
} 
SALINERO, Sebastián. "El crimen organizado en Chile. Una aproximación criminológica al perfil del delincuente a través de un estudio a una muestra no representativa de condenados por delitos de tráfico de estupefacientes".

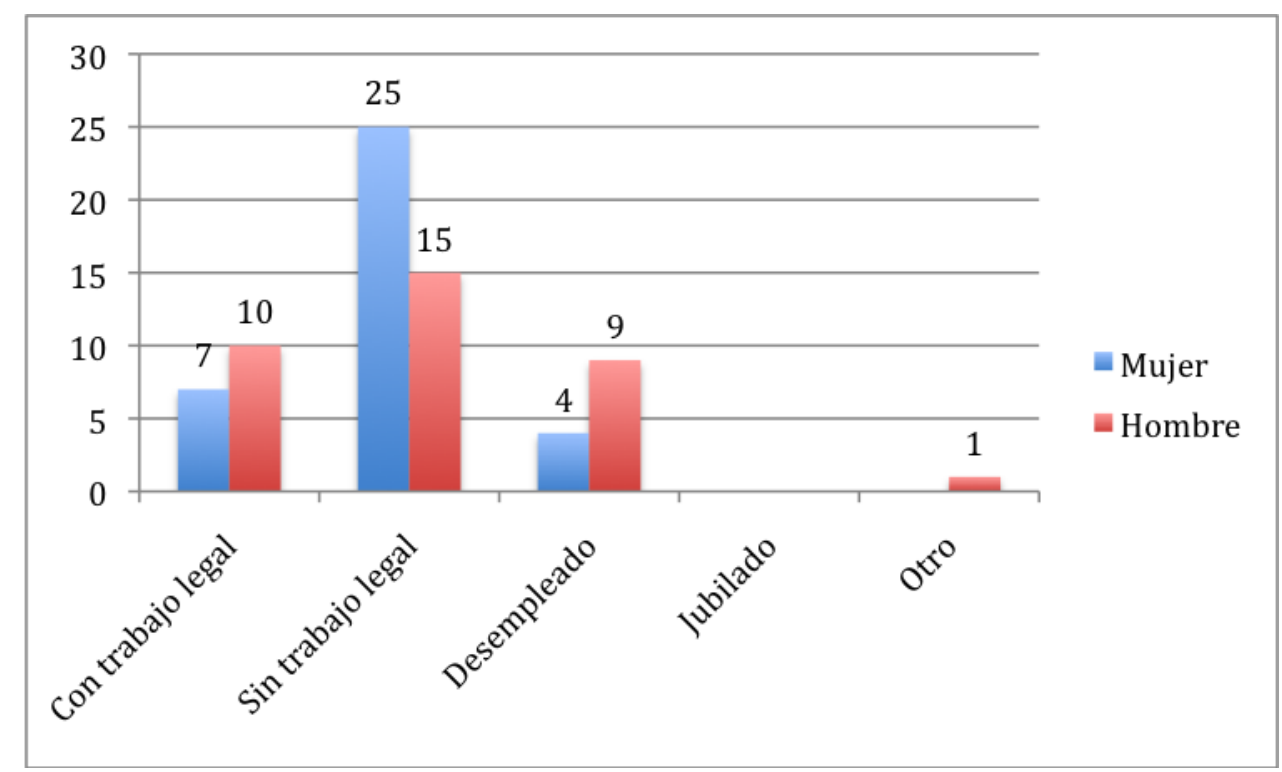

Gráfico 7. Actividad laboral

Lo otro importante de resaltar es la amplia supremacía de los sujetos que señalaron no tener un título profesional (universitario o técnico), los que alcanzaron al $97 \%$. Sin embargo es importante de destacar que las dos personas que indicaron ser profesionales, señalaron ser miembros de confianza al interior de la organización criminal y no ostentaban antecedentes penales pretéritos.

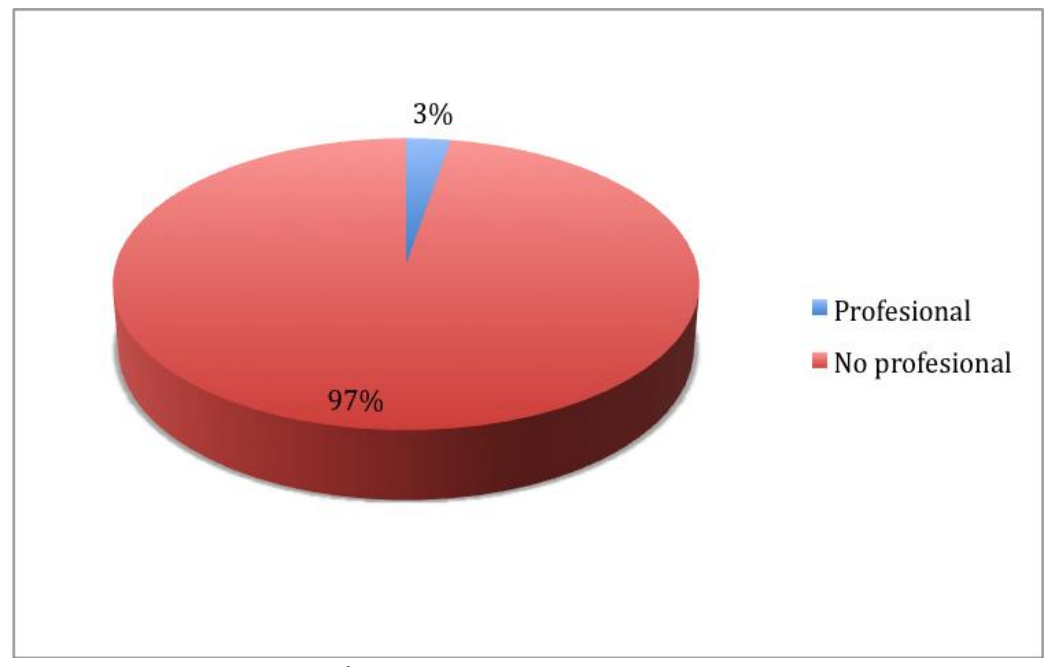

Gráfico 8. Título profesional

\subsection{Carrera delictiva previa.}

Antes de exponer los resultados, debemos aclarar que para los efectos de nuestro estudio las carreras delictivas de los entrevistados se establecieron mediante el conocimiento de los antecedentes penales del sujeto respectivo y no a través de los antecedentes policiales del mismo. La diferencia no es menor, mientras los primeros son el resultado de una condena 
Polít. crim. Vol. 10, No 19 (Julio 2015), Art. 2, pp. 25-55.

[http://www.politicacriminal.cl/Vol_10/n_19/Vol10N19A2.pdf]

penal que consta en el registro respectivo, los segundos responden a meras pesquisas policiales que no necesariamente terminan con una sentencia de un tribunal con competencia en materia penal ${ }^{51}$.

Dicho lo anterior, debemos indicar que la variable carrera delictiva se presentó como una de las más equiparadas, con el $51 \%$ de la muestra que reconoció tener antecedentes penales, frente al 4 9\% que declaró no tenerlos. En su distribución por género también presenta la misma igualdad: mujeres con antecedentes llegaron al $50 \%$ y hombres con antecedentes al $51 \%^{52}$.

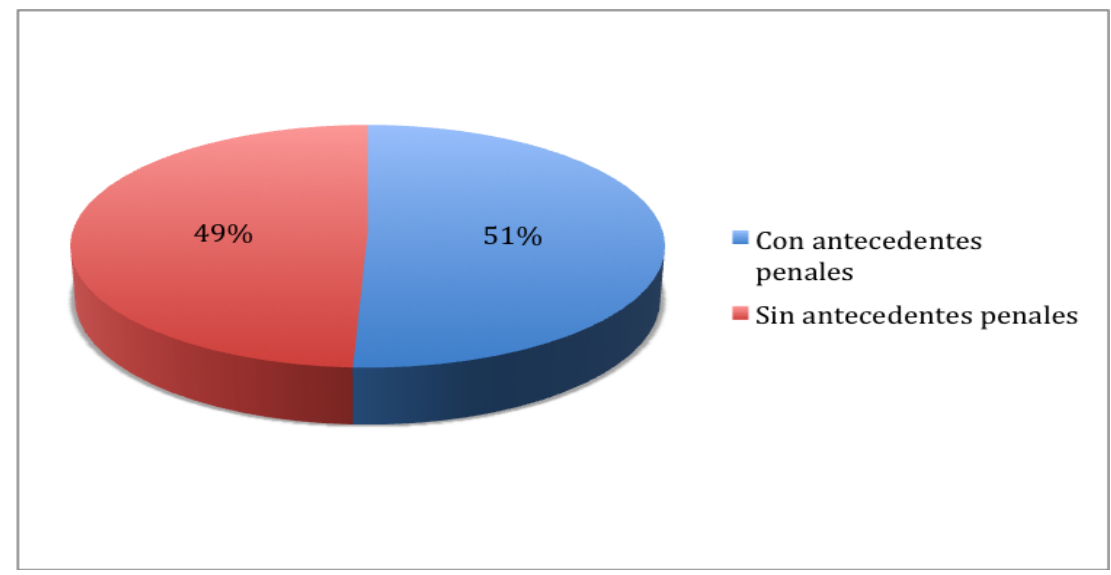

Gráfico 9. Antecedentes penales

\subsection{Condena y abogado defensor.}

Bajo este epígrafe pretendemos revelar la especie de delitos -de aquellos de la ley de drogas- por los cuales los confesantes de pertenecer a una organización criminal declararon, en definitiva, haber sido condenados y por el que se encuentran purgando una pena privativa de libertad; y saber si en los procesos judiciales respectivos donde intervinieron fueron defendidos por abogados particulares o por la Defensoría Penal Pública, y con ello poder inferir si estos cuerpos organizativos podrían proveer asistencia legal a sus integrantes.

En concreto, del total de la muestra, su inmensa mayoría con un índice del $83 \%$ declaró estar sólo condenado por delito de tráfico de grandes cantidades de droga; le sigue los que confesaron estar condenados por tráfico de pequeñas cantidades, que llegaron al $17 \%$; y finalmente ninguno reportó estar condenado por otro delito.

\footnotetext{
${ }^{51}$ En Chile el registro de condenas es llevado por el Registro Civil e Identificación, servicio dependiente del Ministerio de Justicia, en un libro denominado Registro General de Condenas, donde se inscriben las anotaciones penales que afectan a un individuo.

${ }^{52}$ En Giménez-Salinas y otros se estableció que el $77 \%$ de la muestra tenía antecedentes policiales previas y el $23 \%$ no presenta ningún antecedente. GIMÉNEZ-SALINAS/REQUENA/DE LA CORTE, “¿Existe un perfil", cit. nota ${ }^{\circ} 13$, p. 24.
} 
SALINERO, Sebastián. "El crimen organizado en Chile. Una aproximación criminológica al perfil del delincuente a través de un estudio a una muestra no representativa de condenados por delitos de tráfico de estupefacientes".

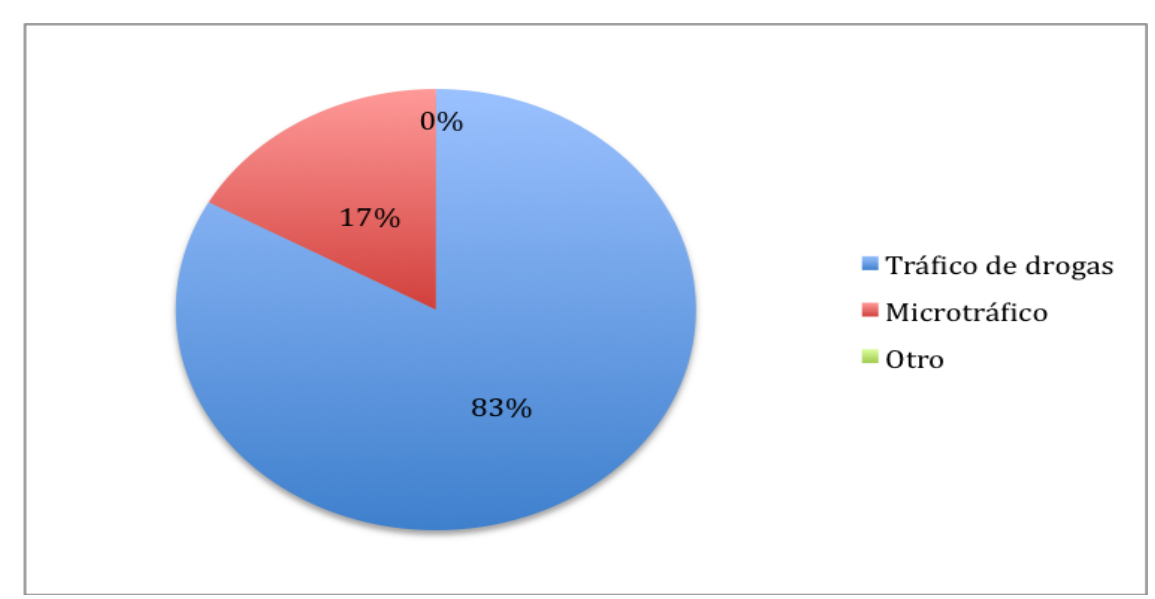

Gráfico 10. Tipología delictiva

En cuanto a la pregunta de qué calidad tenía el abogado que defendió los intereses del encuestado en el juicio, en particular saber si era un defensor privado o público, hubo un marcado predominio de abogados de la Defensoría Penal Pública con un $66 \%$, frente al 34 $\%$ de los abogados privados. En la distribución por género y el tipo de defensa legal también se presenta la misma tendencia.

Lo otro interesante de destacar es que si se correlacionan las variables de tipo de abogado con la del cargo que el encuestado ocupa en la organización criminal, pero sólo referido a líder, jefe secundario y financista, tenemos como resultado que de los 10 casos habidos, el $90 \%$ fue asumido por defensores privados.

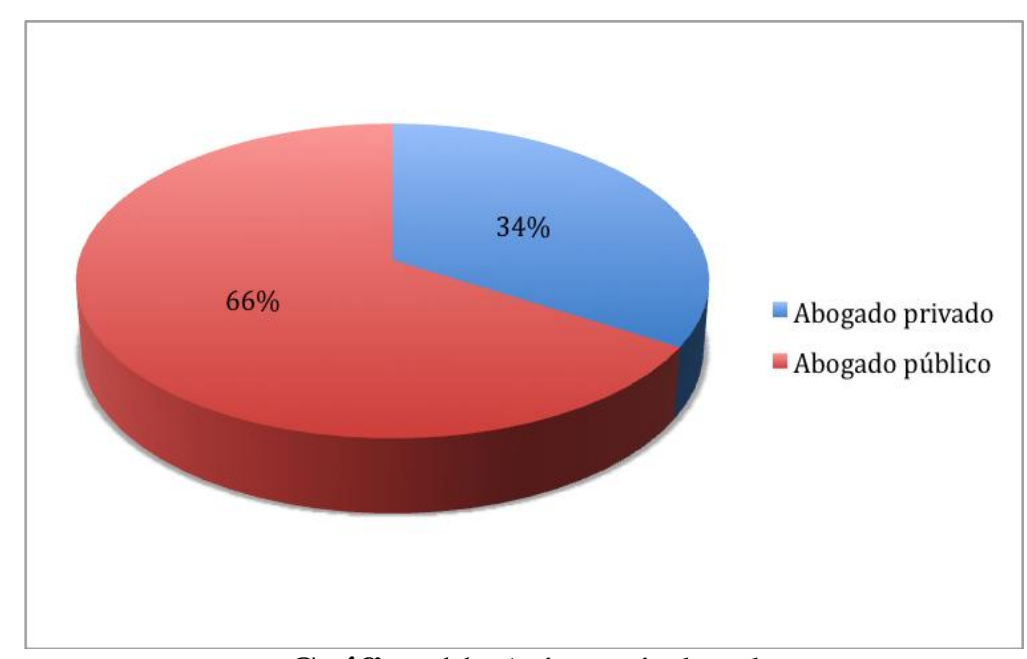

Gráfico 11. Asistencia legal

\subsection{Jerarquía al interior de la organización criminal.}

La variable de "jerarquía" es fundamental tratándose de una organización criminal. Es sin duda uno de sus elementos esenciales, tanto así que podemos afirmar que no se puede 
Polít. crim. Vol. 10, № 19 (Julio 2015), Art. 2, pp. 25-55.

[http://www.politicacriminal.cl/Vol_10/n_19/Vol10N19A2.pdf]

concebir una organización criminal como tal, sin la existencia de una estructura jerarquizada de sus miembros.

Del total de la muestra que reconoció su pertenencia a una organización criminal, el 7 \% (5) señaló ser líder, el $6 \%$ (4) jefe secundario, el $17 \%$ (12) miembro de confianza, la gran mayoría representada por el $55 \%$ (39) dijo ser sólo miembro, el $2 \%$ (1) financista y un 14 $\%$ (10) indicó realizar otra función que no individualizaron y no pudimos determinar ${ }^{53}$.

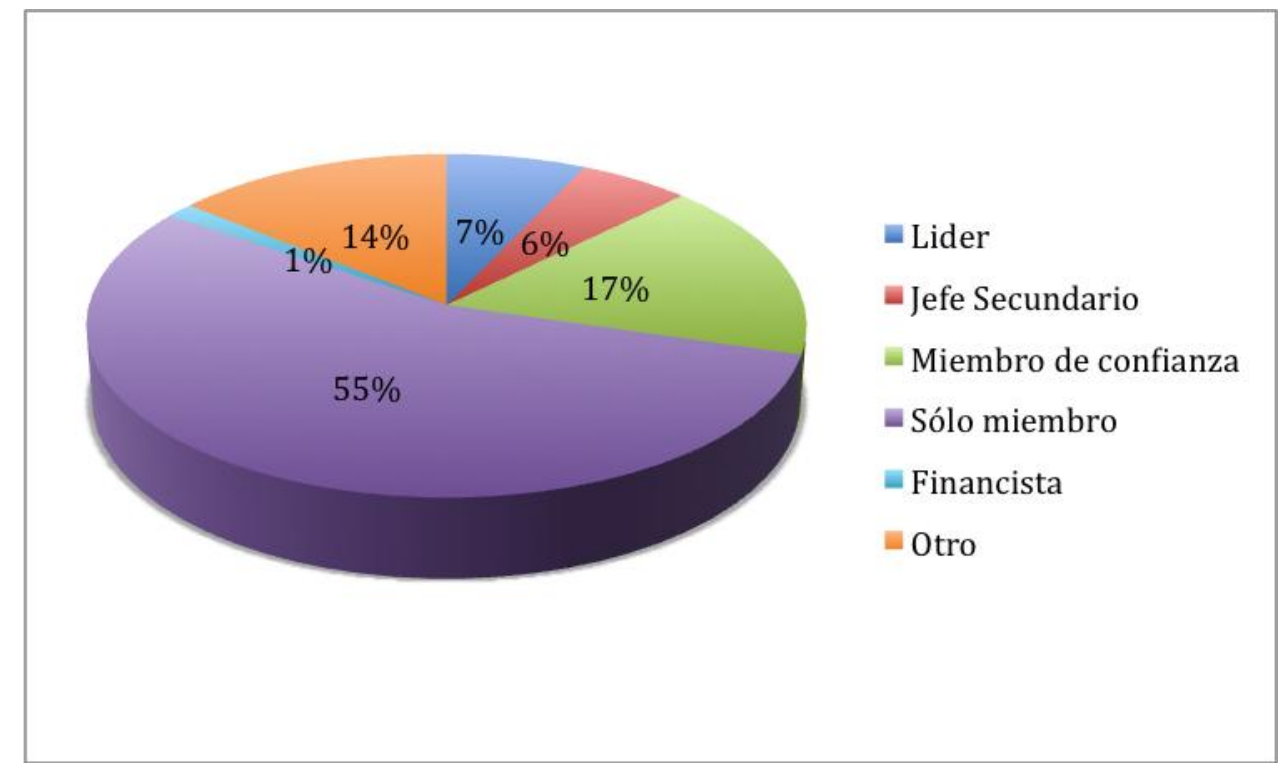

Gráfico 12. Posición jerárquica

Por otro lado, al correlacionar la variable de jerarquía con género y edad, encontramos importantes descubrimientos, como que los cargos de líder son ocupados en su mayoría por hombres ( 4 casos), pero no obstante ello, la mujer también ocupa ese sitial (1 caso). Con respecto al cargo de "Jefe secundario" evidenciamos que de los 4 casos habidos, ellos en su totalidad son ocupados por mujeres. En lo referente a la edad de los que ostentaban los puestos de líder y una jefatura secundaria, no se estableció ningún patrón determinante que pudiese marcar alguna tendencia, ya que los casos que se precisaron recorrían la escala etárea situada entre los 26 y 60 años. Lo único que se puede afirmar es que no se detectaron casos de puestos de liderazgo a temprana edad (escala $18-25$ años) ${ }^{54}$.

\subsection{Permanencia en la organización criminal.}

Otro elemento de la esencia en toda organización criminal es su permanencia en el tiempo para el cumplimiento de sus propósitos delictivos. En otras palabras, la organización criminal está concebida como una empresa para delinquir.

\footnotetext{
${ }^{53}$ En el estudio de Giménez-Salinas y otros se constató que el 6,7 \% de la muestra tenía la condición de líder, el 3,1 \% dijo ser jefe secundario, el 2,9\%, hombre de confianza, y la gran mayoría con un 87,2 \% señaló ser sólo miembro. GIMÉNEZ-SALINAS/REQUENA/DE LA CORTE, “¿Existe un perfil”, cit. nota n 13, p. 25.

54 En Giménez-Salinas y otros se corroboró lo que intuitivamente pareciera existir tratándose de organizaciones criminales, como que las jefaturas son ocupadas por las personas mayores. GIMÉNEZSALINAS/REQUENA/DE LA CORTE, “¿Existe un perfil”, cit. nota n 13, p. 14.
} 
SALINERO, Sebastián. "El crimen organizado en Chile. Una aproximación criminológica al perfil del delincuente a través de un estudio a una muestra no representativa de condenados por delitos de tráfico de estupefacientes".

Ante la pregunta de saber cuánto tiempo llevaba el encuestado formando parte de la organización criminal, existió una clara supremacía de la opción menos de 1 año con un 58 $\%$ de los casos; seguida por los que declararon pertenecer entre 1 y 5 años, que fue el $38 \%$; y finalmente un marginal $4 \%$ declaró llevar más de 5 años en la organización, pero con la especial característica de que se trataba sólo de mujeres, de las cuales una era líder y las dos restantes sólo eran miembro.

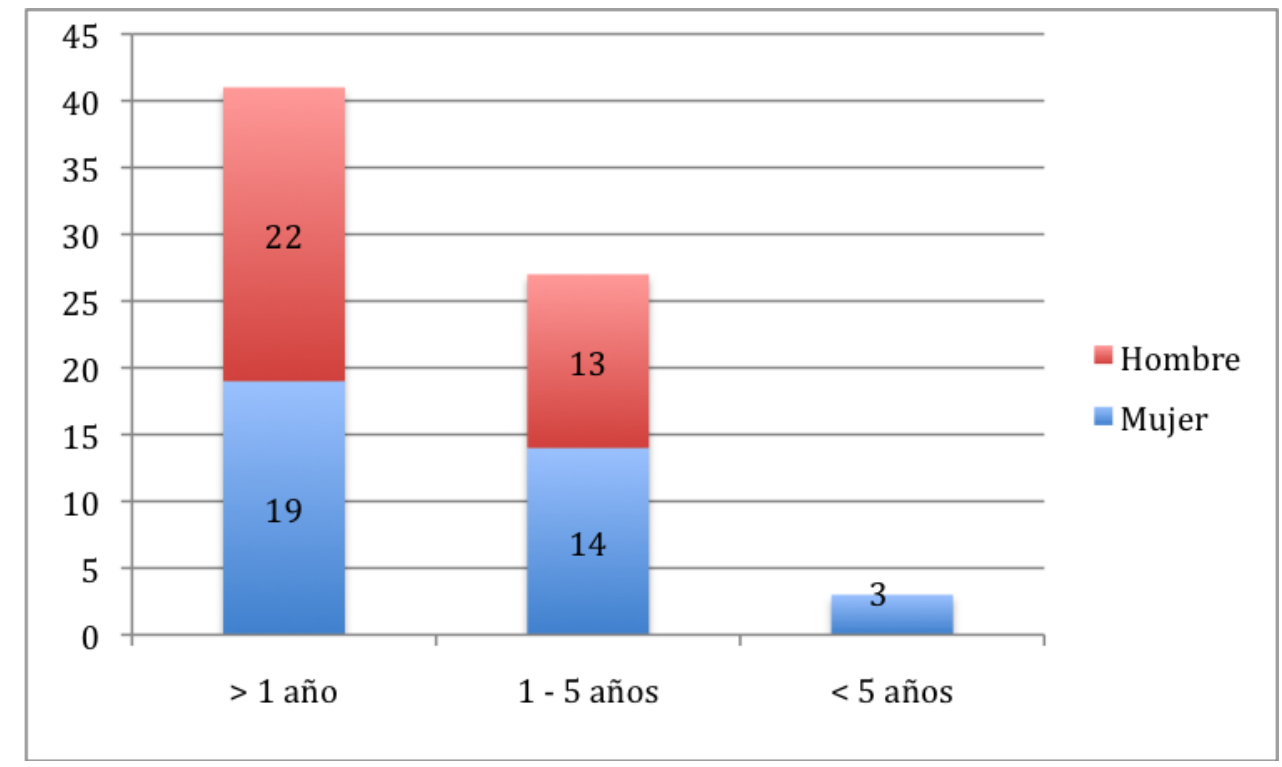

Gráfico 13. Permanencia y género

\subsection{Negocios de la organización criminal (y sustancia traficada).}

Por último, también es un requisito sine qua non de toda organización criminal dedicarse o tener por objeto la realización de negocios ilícitos. Todo sin perjuicio de que pueda operar bajo un manto de licitud en el desarrollo de sus actividades para no llamar la atención de los órganos encargados del control formal.

En nuestro estudio pudimos advertir que la gran mayoría, ascendente a un $87 \%$, señaló que la organización sólo se dedicaba al negocio de la droga, y el 13 \% restante manifestó que se encontraba abierta a otras actividades ilícitas. 
Polít. crim. Vol. 10, № 19 (Julio 2015), Art. 2, pp. 25-55.

[http://www.politicacriminal.cl/Vol_10/n_19/Vol10N19A2.pdf]

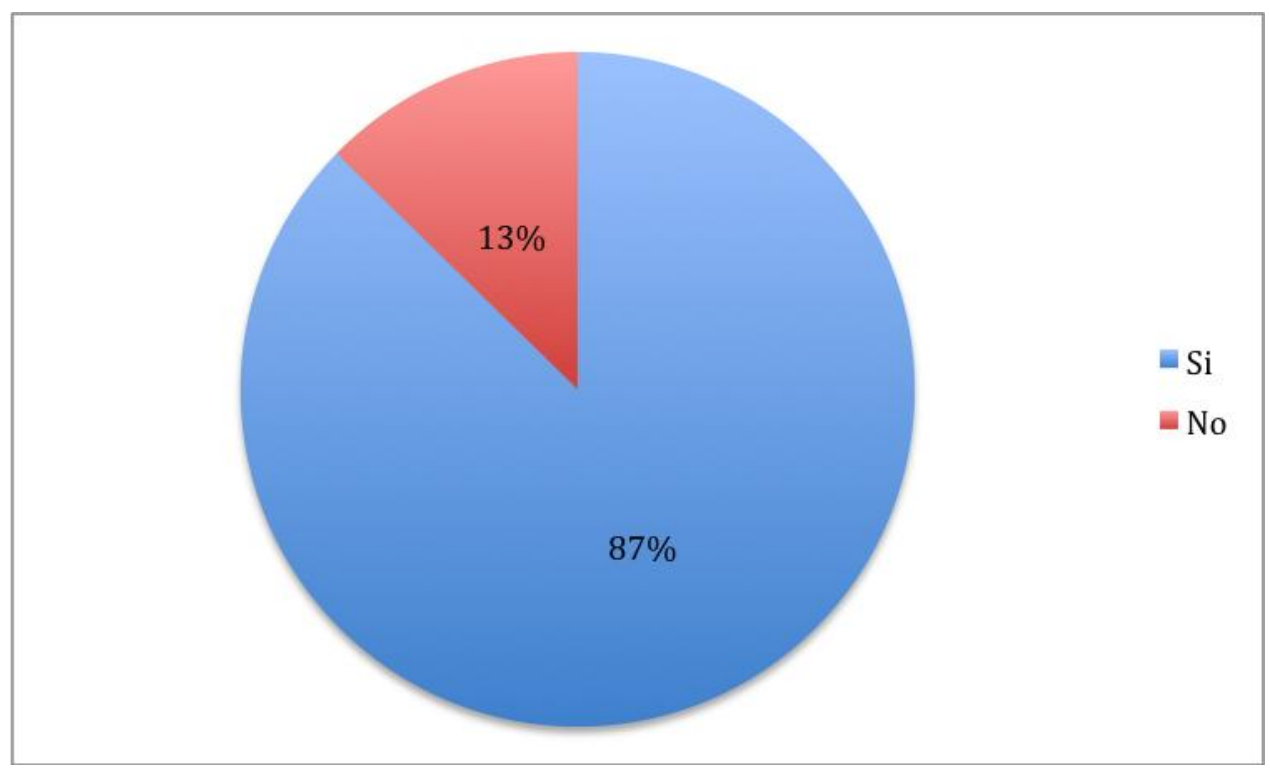

Gráfico 14. Objeto exclusivo negocio de la droga

La otra variable que intentamos medir a propósito del crimen organizado que se dedica al negocio del narcotráfico, era poder determinar cuál era la sustancia estupefaciente predilecta de comercializar. La respuesta se enmarcó dentro de lo intuitivo y específicamente en la relación existente entre droga y ganancia. La cocaína resultó ser la sustancia más tranzada por estas organizaciones, con un $62 \%$ de las preferencias; seguida por uno de sus derivados (pasta base), con un $30 \%$; y para terminar la marihuana (cannabis sativa) con un $8 \%$ de las preferencias ${ }^{55}$.

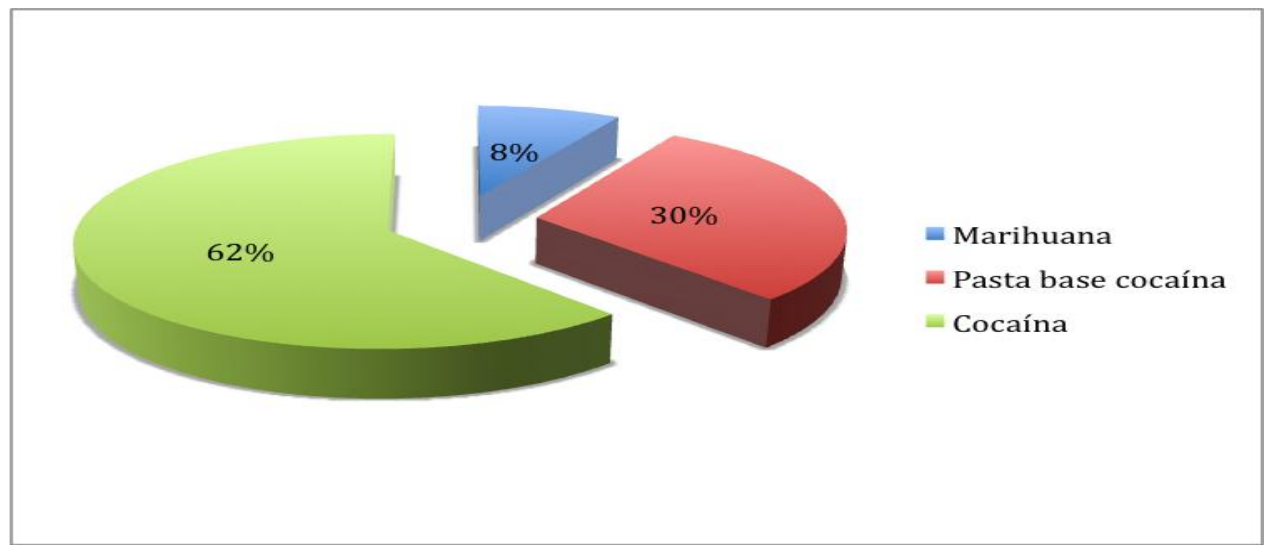

Gráfico 15. Tipo de droga comercializada

\footnotetext{
${ }^{55}$ En el estudio de Giménez-Salinas y otros, en lo que al mercado de las drogas se refiere, el panorama lo domina el tráfico de cocaína y le sigue el Hachís. GIMÉNEZ-SALINAS/REQUENA/DE LA CORTE, “Existe un perfil”, cit. nota n ${ }^{\circ} 13$, p. 16.
} 
SALINERO, Sebastián. "El crimen organizado en Chile. Una aproximación criminológica al perfil del delincuente a través de un estudio a una muestra no representativa de condenados por delitos de tráfico de estupefacientes".

\section{Discusión.}

Ante todo hay que destacar la buena disponibilidad de los encuestados y la seriedad con que asumieron esta investigación. Si bien pudiese existir algún cuestionamiento sobre la veracidad de las respuestas entregadas, las que dicho sea de paso se podría presentar en cualquier tipo de encuesta, es nuestra creencia como dijimos anteriormente, esta presumiblemente se pudiese encontrar en el límite inferior de los que asumieron pertenecer a una organización criminal, es decir, el número de encuestados que podrían estar adscritos a este tipo de entidad asociativa podrían ser más que los que efectivamente así lo declararon.

En cuanto a los datos obtenidos, cabe resaltar primeramente el elevado índice de encuestados $(35,5 \%)$ que declararon su pertenencia a una organización criminal al momento de cometer el delito y, en segundo lugar, la destacada presencia de mujeres en estos aparatos organizativos (51\%), a pesar de su evidente sobrepoblación.

En cuanto a la distribución etárea, ambos grupos de género presentan marcadas diferencias. Mientras el $50 \%$ de las mujeres que declararon ser parte de una organización criminal se sitúan preferentemente en el tramo de 18 y 32 años; los hombres, a su vez, se encuentran mayoritariamente en el tramo comprendido entre los 33 y 50 años, con un índice del $63 \%$. Esto denota, a partir de esta muestra encuestada, una diferencia importante en el ingreso por sexo a estas organizaciones, mientras las mujeres lo hacen mayoritariamente a temprana edad, los varones en cambio se incorporan en una edad más adulta.

La nacionalidad es sin duda otra variable a destacar. Del total de extranjeros encuestados, el 95\% declaró pertenecer a una organización criminal y, de ellos, la presencia de mujeres es absolutamente predominante. También destaca en este ámbito que prácticamente dos tercios de los foráneos ingresan al país de manera irregular, lo que denota de cierta manera, a propósito del tráfico de drogas, un carácter de clandestinidad.

El estado civil en el crimen organizado es una variable que, conforme a la muestra encuestada, no presenta muchas diferencias con respecto a la criminalidad común. Por su parte, la paternidad se presenta como opción mayoritaria (superior al $80 \%$ ) y practicamente todos los encuestados declararon pertenecer a un grupo familiar en número importante.

En relación al mercado del trabajo y su correlación con los encuestados que declararon pertenecer a una organización criminal, destacan tres situaciones: la primera, referente al alto índice $(56 \%)$ de los que indicaron dedicarse únicamente a un quehacer ilegal; la segunda, la importante presencia de las mujeres $(69 \%)$ en ese ámbito; y tercero, la presencia en estas organizaciones delictuales de personas que poseen un trabajo legal. Finalmente, aunque marginal, destaca la presencia de personas profesionales en estas organizaciones, ocupando generalmente puestos de confianza en el seno de estas instituciones. 
Polít. crim. Vol. 10, № 19 (Julio 2015), Art. 2, pp. 25-55.

[http://www.politicacriminal.cl/Vol_10/n_19/Vol10N19A2.pdf]

En lo que respecto a la carrera delictiva previa de los encuestados, la muestra se presenta bastante heterogénea y proporcional entre los que declararon tener antecedentes penales (51 $\%)$ y los que no. A su vez, la gran mayoría señaló haber sido únicamente condenado por un delito de tráfico de drogas de grandes cantidades $(83 \%)$ y el saldo restante por tráfico de pequeñas cantidades. También destaca, a propósito de la defensa legal, que la supremacía de los encuestados declaró una asistencia letrada de carácter pública (66\%).

La jerarquía al interior de la organización criminal fue otra variable medida en la encuesta que tuvo interesantes resultados. No solo se avizoró una efectiva organización al interior de esta estructura delictiva (el $7 \%$ señaló ser líder, el $6 \%$ jefe secundario, el $17 \%$ miembro de confianza, la gran mayoría representada por el $55 \%$ dijo ser sólo miembro, el $2 \%$ financista y un $14 \%$ indicó realizar otra función que no se individualizó) por parte de los encuestados, sino también una presencia del género femenino en los puesto de liderazgo de la estructura organizativa (líder y jefes secundario).

Otra característica importante de las organizaciones criminales es su permanencia en el tiempo. Variable respecto de la cual se pudo establecer que los encuestados que declararon afirmativamente pertenecer a ella, llevaban en su mayoría poco tiempo de permanencia (58 $\%$ ), y los que, a su vez, tenían un mayor tiempo (cifra marginal ascendente al $5 \%$ ), eran en su totalidad mujeres.

Para terminar, si bien los encuestados pertenecían a organizaciones que se dedicaban al narcotráfico, se confirmó que la gran mayoría (87\%) de estas organizaciones se dedicaba exclusivamente al negocio de la droga y solo una cifra menor (13\%) estaba abierta a otros negocios ilícitos. Ahora bien, resultó ser la cocaína y su precursor (pasta base de cocaína) las sustancias más traficadas por estas organizaciones criminales (92\%).

\section{Conclusiones.}

Hemos logrado una primera aproximación al perfil del delincuente organizado nacional a partir de los datos proporcionados por el propio participe en estas estructuras organizativas, constituyéndose de esta manera como un probable método idóneo de investigación científica que debería ser colacionado con el estudio de expedientes criminales como se evidencia en la experiencia comparada y con estudios cualitativos que permitan una mayor caracterización de este tipo de delincuencia. De esta manera, hemos determinado la necesidad de seguir investigando con mayor profundidad y con nuevas metodologías la delincuencia organizada y, así, corroborar de mejor manera algunos enunciados sostenidos en este trabajo. Así, verbigracia, se debería establecer en base a una muestra estratificada de mujeres su representación en estos aparatos organizativos.

En cuanto a lo medular, y teniendo presente el carácter exploratorio de nuestro trabajo, que sus resultados no pueden ser interpretados, de modo alguno como representativos, interesa destacar la importante cantidad de encuestados que confesó su pertenencia a una organización criminal en nuestro país; también se vislumbró una destacada presencia de mujeres en estos aparatos organizativos, a pesar de su sobrerrepresentación y el sesgo que ello podría implicar, hecho que podría tener relación con que probablemente el narcotráfico 
SALINERO, Sebastián. "El crimen organizado en Chile. Una aproximación criminológica al perfil del delincuente a través de un estudio a una muestra no representativa de condenados por delitos de tráfico de estupefacientes".

es un delito en que las féminas tienen una sintomática participación (así lo demuestran las cárceles chilenas), por lo que para corroborar esta hipótesis se debería investigar organizaciones con objeto delictivo diverso al mercado de las drogas, para verificar si se trata de una constante que predomina en estas organizaciones o tiene más bien una vinculación al ilícito.

Por otro lado, se pudo advertir del grupo de encuestados que los participantes en estos aparatos organizativos eran en su mayoría de las escalas etáreas superiores y no hay una presencia a temprana edad (jóvenes). También y preocupante por cierto, es el hecho que los casos pesquisados de crimen organizado, los encuestados sólo fueron condenados por el delito o actividad a la cual la organización se dedica (narcotráfico) y no por su pertenencia a una estructura organizada y funcionalmente delictiva. Situación que hace un llamado de atención a las autoridades sobre si los instrumentos legales son político-criminalmente correctos para la prevención, persecución y sanción de estas organizaciones.

También pudimos advertir la importante presencia de extranjeros en el grupo encuestado, lo que se conecta de cierta manera con la transnacionalidad de éstas instituciones delictivas. Al respecto se presentaron dos características destacables respecto de los extranjeros encuestados, como es en primer lugar la también patente presencia de mujeres en estas corporaciones y, en segundo lugar, el mayoritario ingreso ilegal al país lo que hace presumir de cierta manera un componente de ausencia de proyecto migratorio.

Por último, al igual que lo sostiene el estudio comparado, tantas veces citado de GiménezSalinas y otros, no es posible establecer un perfil único de delincuente en las organizaciones criminales, y tampoco es posible sostener que alguna teoría etiológica pudiese explicar estas entidades delictivas. Lo único claro por cierto, es que el fenómeno del crimen organizado requiere de más y mejores estudios criminológicos. 
Polít. crim. Vol. 10, № 19 (Julio 2015), Art. 2, pp. 25-55.

[http://www.politicacriminal.cl/Vol_10/n_19/Vol10N19A2.pdf]

\section{BIBLIOGRAFÍA}

ABADINSKY, Howard, Researching Organized Crime - Methodological Problems. Cullowhee, NC: Western Carolina University (1981). , Organized crime 10 ${ }^{\mathrm{a}}$ Ed. Belmont: Wadworth (2013).

ALBANESE, Jay, Organized Crime. In our times. $6^{\mathrm{a}}$ Ed. Newark: Anderson Publishing (2011).

BLOCK, Richard, "Community, environment and violent crime”, Criminology, 17 (1979), pp. 46-57.

CARNEVALI, Raúl, "La criminalidad organizada. Una aproximación al Derecho penal italiano, en particular la responsabilidad de las personas jurídicas y la confiscación", Revista Ius et Praxis, Año 16), no 2 (2010), pp. 273-330.

, "Las organizaciones criminales. Algunas cuestiones a considerar para su configuración”, Doctrina y Jurisprudencia Penal. Universidad de Los Andes, no 14 (2013), pp. 3-22.

FARRINGTON, David, "The explanation and prevention of youthful offending" en: CORDELLA, Peter; SIEGEL, Larry (Eds.), Reading in contemporary criminological theory. Boston: Northeastern University Press, 1996.

FRANCIS, Brian; HUMPHREYS, Leslie; KIRBY, Stuart; SOOTHILL, Keith, "Undestanding criminal careers in organized crime", Home Office, Reporte 74, Octubre, 2013, pp. 1-120.

GARCÍA-PABLOS DE MOLINA, Antonio, Tratado de Criminología, $4^{\mathrm{a}}$ Ed. Valencia: Tirant lo Blanch, 2009.

GIMÉNEZ-SALINAS, Andrea; DE LA CORTE, Luis; REQUENA, Laura; DE JUAN, Manuel "La medición y evaluación de la criminalidad organizada en España: ¿Misión imposible?". Revista Española de Investigación Criminológica, № 9 (2009), pp. 128.

GIMÉNEZ-SALINAS, Andrea; REQUENA, Laura; DE LA CORTE, Laura, “Existe un perfil de delincuente organizado? Exploración a partir de una muestra española", Revista Electrónica de Ciencia Penal y Criminología, 13-3 (2011), pp. 1-32.

GIMÉNEZ-SALINAS, Andrea, "La delincuencia organizada en Europa: Extensión, factores facilitadores y rasgos principales", Documentos de seguridad y defensa, $\mathrm{N}^{\mathrm{o}}$ 48 (2012), pp. 11-32.

"El crimen organizado", Ediciones Universidad Oberta de Cataluña, Barcelona, 2013, pp.1-58.

HALLER, Mark, "Illegal Enterprise: A theoretical and historical interpretation", Criminology, 28, (1990), pp. 207-236.

HASSEMER, Winfried; MUÑOZ CONDE, Francisco, Introducción a la Criminología, Valencia: Tirant lo Blanch, 2001.

KLEEMANS, Edward R.; DE POOT, Christianne J., "Criminal Careers in Organized Crime and Social Opportunity Structure", European Journal of Criminology, 5 (2008), pp. 69-98.

LANDESCO, John, Organized crime in Chicago. $2^{\mathrm{a}}$ Ed. Chicago: University of Chicago Press, 1969.

LYMAN, Michael; POTTER, Gary, Organized Crime, $4^{\mathrm{a}}$ Ed., New Jersey: Prentice Hall, 2007. 
SALINERO, Sebastián. "El crimen organizado en Chile. Una aproximación criminológica al perfil del delincuente a través de un estudio a una muestra no representativa de condenados por delitos de tráfico de estupefacientes".

MUELLER, Gerhard, "Transnational crime: Definitions and concepts”, en: WILLIAMS, Phil; VLASSIS, Dimitri (Eds.), Combating transnational crime. Concepts, activities and responses", Londres: Frank Cass, 2001.

POTTER, Gary; JENKINS, Philip, The City and the Syndicate: Organizing Crime in Philadelphia. Lexington, MA: Ginn Press, 1985.

SAMPSON, Robert; LAUB, John, Crime in the Making: Pathways and turning points through life. Cambridge: Harvard University Press, 1993.

SUTHERLAND, Edwin; CRESSEY, Donald, Principles of criminology. $10^{\mathrm{a}}$ Ed. Philadelphia: Lippincott, 1978.

VAN DIJK, Jan; NEVALA, Sami, "Results of an analysis of the correlations between indices of different types of conventional and non-conventional crime", en: NIEUWBEERTA, P. (Ed.), Crime victimization in international perspective: results from the international crime victims survey, 1989-2000. Den Haag: Boom Juridische Uitgevers, 2002 pp. 183-193.

VAN DIJK, Jan, "Mafia markers: assessing organized crime its impact upon societies", Trends in Organized Crime, 10 (2007), pp. 39-56.

VÁSQUEZ, Carlos; SERRANO, María Dolores, Derecho penal juvenil. $2^{\mathrm{a}}$ Ed. Madrid: Dykinson, 2007.

VOLD, George; BERNARD, Thomas; SNIPES, Jeffrey, Theoretical Criminology, $5^{\mathrm{a}}$ Ed., New York: Oxford University, 2002.

Carabineros de Chile Dirección Investigación Delictual y Drogas Departamento Investigación de Organizaciones Criminales "Situación actual de las pandillas juveniles en Chile", agosto (2008). En http://ciperchile.cl/wpcontent/uploads/informe-os9.pdf

Estadísticas Policía de Investigaciones de Chile 2012. En http://www.ine.cl/canales/menu/publicaciones/calendario de publicaciones/pdf/inves tigaciones_2012.pdf

Federal Bureau of Investigation. En: www.fbi.gov/aboutus/investigate/organizedcrime/glossary.

Informe Realidad Nacional del Crimen Organizado Transnacional, Biblioteca del Congreso Nacional. 
Polít. crim. Vol. 10, № 19 (Julio 2015), Art. 2, pp. 25-55.

[http://www.politicacriminal.cl/Vol_10/n_19/Vol10N19A2.pdf]

\begin{abstract}
Anexo 1
Hola, estamos haciendo un estudio para el Centro de Estudios de Derecho Penal de la Universidad de Talca sobre organizaciones delictivas en Chile, le haré, si Ud. quiere un cuestionario de 16 preguntas. Le aclaro, que no le preguntaré por nombres, direcciones u otros antecedentes personales y que todo lo que me diga corresponderá a información secreta que no se develará y lo único que realizaré con lo aquí me diga, dice relación con confeccionar estadísticas, como por ejemplo: el 60\% de la muestra era de sexo masculino. ¿Quiere participar?
\end{abstract}

Entendiendo por una organización criminal: "un grupo estructurado de tres o más personas que existe durante cierto tiempo y que actúa concertadamente con el propósito de cometer uno o más delitos graves, con miras a obtener, directa o indirectamente, un beneficio económico u otro beneficio de orden material".

1.- Sexo: $\mathrm{M} / \mathrm{F}$

2.-Edad: 18-25 / 26-32 / 33-40 / 41-50/ 51-60/ más de 60

3.- Nacionalidad Chileno / Extranjero Extranjero Ingreso como: turista/ residente/ ilegal/ otro

4.- Oficio/ocupación: Profesional/ No Profesional

5.- Trabaja: Con trabajo legal/ Sin trabajo legal/ Desempleado/ Jubilado/otro

6.- Estado civil: Casado/Convive/Soltero/Viudo/

7.- Grupo familiar: Sólo 1 personas/ Entre 2 y 4/ más de 5 personas

8.- Es padre o madre: $\mathrm{Si} / \mathrm{No}$

9.-Situación económica: ¿Qué opina del nivel de ingreso en su hogar? Satisfecho/Bastante satisfecho/insatisfecho/Muy insatisfecho

10.- Antecedentes penales: $\mathrm{Si} / \mathrm{No}$

11.- Condenado por delito de: tráfico de drogas/microtráfico/Otro Sustancia:

12.- Lo defendió un abogado particular o público: Particular/Público

Organización Criminal:

No le voy a pedir nombres ni antecedentes privados

13.1 ¿Cuándo cometió el delito, Ud. pertenecía a una organización? Si (pasar a 9.2) No (terminar)

13.2 ¿Qué puesto ocupaba: líder/ jefe secundario/ miembro de confianza,/sólo miembro/ financista/Otro

13.3 ¿Cuánto tiempo lleva en esta organización? Menos de un año/ más de un año y menos de cinco/ más de cinco años

13.3 ¿La organización sólo se dedicaba al negocio de la droga? Si/No 